Research papers

\title{
Did streamflow or suspended sediment concentration changes reduce sediment load in the middle reaches of the Yellow River?
}

\author{
Jianjun Zhang ${ }^{\mathrm{a}, \mathrm{b}, \mathrm{c}}$, Xiaoping Zhang ${ }^{\mathrm{a}, *}$, Rui Li ${ }^{\mathrm{a}}$, Lili Chen ${ }^{\mathrm{a}}$, Pengfei Lin ${ }^{\mathrm{a}, \mathrm{c}}$ \\ ${ }^{a}$ State Key Laboratory of Soil Erosion and Dryland Farming on the Loess Plateau, Institute of Soil and Water Conservation, Chinese Academy of Sciences and Ministry of \\ Water Resources, Yangling, Shaanxi 712100, China \\ ${ }^{\mathrm{b}}$ State Key Laboratory of Urban and Regional Ecology, Research Center for Eco-Environmental Sciences, Chinese Academy of Sciences, Beijing 100085, China \\ ${ }^{\mathrm{c}}$ University of Chinese Academy of Sciences, Beijing 100049, China
}

\section{A R T I C L E I N F O}

\section{Article history:}

Received 15 February 2015

Received in revised form 30 December 2016

Accepted 3 January 2017

Available online 7 January 2017

This manuscript was handled by $A$.

Bardossy, Editor-in-Chief

\section{Keywords:}

Ecological restoration

Sediment yield

Suspended sediment concentration

Streamflow

Loess Plateau

\begin{abstract}
A B S T R A C T
The continuous ecological restoration of the Loess Plateau, which aims to reduce the sediment entering into the Yellow River, is known throughout the world for two strategies: the integrated soil conservation project that began in the 1970s, and the "Grain for Green" project that began in the 1990s. However, the topic of whether the muddy water in the middle Yellow River run clearer remains debatable, and, in fact, response to the topic is reasonably well documented in regard to hydrological changes in the sediment source area. Six sub-catchments nested in the Beiluo River basin - one of the major sediment sources for the Yellow River - were selected, with data series ranging from 1957 to 2009. The Mann-Kendall and Pettitt tests were used for trend detection. A simple method was developed based on the distribution of suspended sediment concentration (SSC) versus water discharge. Using this method, we evaluated the quantities of sediment yield reduction attributed to streamflow and SSC changes due to the two strategies.

The results showed that annual sediment yield in 5 out of 6 stations significantly decreased, with rates varying from -4 to $-217 \mathrm{t} \cdot \mathrm{km}^{-2} \cdot \mathrm{yr}^{-1}$. Significant decreases in daily and event streamflow and suspended sediment concentration were identified, especially at a high SSC (top 1-5\%). During the integrated soil conservation period, the sediment yield was reduced mainly by decreases in high flow and high SSC conditions. In contrast, during the "Grain for Green" period, sediment yield was reduced due to decreases in streamflow and SSC at all magnitudes. It was concluded that rainfall-sediment load dynamics have changed in the context of ecological restoration. Changes in both streamflow and the SSC-water discharge relationship induced the sediment yield reduction over time; in other words, the streamflow in the middle reaches of Yellow River became clearer during periods of ecological restoration. Moreover, the increased annual sediment yield at the Zhangcunyi station exposed a risk of increased erosion in areas where forests had been well preserved.
\end{abstract}

(c) 2017 Elsevier B.V. All rights reserved.

\section{Introduction}

The Yellow River is one of the largest contributors of global riverine sediment flux from land to the seas. It has created the broad North China Plain, which is the land that nurtured Chinese civilization throughout history. The sediment load of the Yellow River was estimated to be approximately $0.8 \times 10^{9} \mathrm{t} \cdot \mathrm{yr}^{-1}$ throughout the Holocene, whereas it increased to approximately $1.6 \times 10^{9} \mathrm{t} \cdot \mathrm{yr}^{-1}$ between the 1930s and 1950s (Shi et al., 2002; Shi and Shao, 2000). Research showed that $90 \%$ of the sediment load was carried from the Loess Plateau $\left(640,000 \mathrm{~km}^{2}\right)$, and $41 \%$

\footnotetext{
* Corresponding author.

E-mail addresses: zhangxp@ms.iswc.ac.cn (X. Zhang), lirui@ms.iswc.ac.cn (R. Li).
}

of the total sediment load in recent decades was added due to land use intensification driven by increasing population (Derbyshire et al., 2000; Li, 2003; Shi et al., 2002). Severe sediment erosion and deposition can result in disasters and environmental problems. For example, landslide events are frequently reported by the news media (Derbyshire et al., 2000; Wang and Unwin, 1992; Zhou et al., 2002), and continuous soil erosion slowly deprives the land of fertile soil, leading to reductions in crop production (Cai, 2001; Pimentel et al., 1995). The river bed of the lower Yellow River is 8-10 $\mathrm{m}$ above the surrounding floodplain. The average sediment deposition in the lower reaches was $1.58 \times 10^{8} \mathrm{t} \cdot \mathrm{yr}^{-1}$ from 1950 to 2004 , with an aggradation of $11 \mathrm{~cm} \cdot \mathrm{yr}^{-1}$ (1964-1997) (Wang et al., 2006). This thalweg aggradation poses a major flood hazard to local communities (Shi and Shao, 2000). The sediment deposited 
in the lower reach of the Yellow River mainly comprises coarse sand (grain-size $>0.05 \mathrm{~mm}$ ), which was chiefly delivered from the Coarse Sandy Hilly catchments (Hekou-Longmen region), the Malian River basin and the Beiluo River basin (Tang, 2004). Consequently, these areas are considered the key areas for soil loss and sediment deposition control.

To control severe soil erosion, two ecological restoration projects were progressively implemented in the Loess Plateau in recent decades (Ran et al., 2000; Tang, 2004). The integrated soil conservation project, focusing on the integrated management of small watersheds, has been implemented in the Loess Plateau since the 1970s (Tang, 1993; Ran et al., 2000; Yao et al., 2005). This project consists of engineering works: (1) building sediment-trapping dams, (2) the terracing of farmlands on slopes, and vegetation measures: (1) the replanting of trees and (2) the improvement of pastures (Ran et al., 2000; Yao et al., 2011). As part of this strategy, numerous sediment-trapping dams were built in gullies to intercept sediment loads. To decrease soil erosion on the slopes, an extensive series of measures was adopted, including the terracing of farmland, the planting of trees and the improvement of pastures. The sediment-trapping dam was invented by people in the Loess Plateau of China several centuries ago. Generally, a sedimenttrapping dam comprises three parts: the embankment, the spillway, and the outlet. It generally controls a drainage area varying from several to tens of square kilometers (Xu et al., 2004). By making use of the local geography and climate, it was used to retain sediments and to form farmland. As one of the primary measures for the conservation of water and soil, sediment-trapping dams have been given great emphasis since the 1950s. Approximately 100,000 sediment-trapping dams were built in the late 1960s and 1970s (CMWR, 2003; Wang et al., 2011), and many of them were simply constructed without spillways or outlets.

It was noted that the sediment-trapping dams are the primary measures for reducing sediment load, causing approximately 60$70 \%$ of the reduction (Ran et al., 2000). Unfortunately, an investigation in northern Shaanxi province showed that approximately $80 \%$ of sediment-trapping dams were destroyed in fierce rainstorms in the early 1980s (Xu et al., 2004). With sediment continually pouring into the Yellow River, the emphasis of soil and water conservation in the Loess Plateau was on vegetation measures. Subsequently, the strategy of using sediment-trapping dams was then replaced by the "Grain for Green" strategy. The "Grain for Green" project mainly consists of vegetation measures. It has been implemented by regulating slopes on a massive scale since the 1990s (Ran et al., 2000; Tang, 2004; Yao et al., 2005; Zhang et al., 2014).

The mechanisms for reducing sediment load are different in engineering projects and vegetation measures. For instance, engineering projects can block or delay streamflow, consequently increasing infiltration and depositing the suspended sediment (Mu et al., 2007; Xu et al., 2004; Zhang et al., 1997). Generally, the effects of engineering works on runoff are significant and immediate, as they can more effectively prevent surface runoff, especially that with high flow with high suspended sediment concentration (SSC). However, the engineering projects will lose their effectiveness slowly and eventually be abandoned due to deposition (Ran et al., 2013; Wang et al., 2005, 2011; Xu et al., 2004; Zheng et al., 2005). Hydrographic research showed that areas with extensive natural vegetation normally have little or no erosion, even if the geomorphology is hilly with steep slopes and gullies (Mi, 1982; Shi and Shao, 2000). Vegetation measures can alter the catchment's water balance by increasing rainfall reception and evapotranspiration (Brown et al., 2005; Gao et al., 2012; Zhang et al., 2001a, 2001b). Soil erosion and sediment transport are therefore decreased by decreasing surface runoff, increasing water infiltration and depositing suspended sediment (Quinton et al., 1997; Sahin and Hall, 1996). However, the effect of vegetation measures is usually shown with a lag of years for vegetation recovery and vegetation coverage area accumulation (Gao et al., 2012; Zheng et al., 2005). The effect of appropriate vegetation measures will become more and more significant as time goes by Ran et al. (2013) and Zheng et al. (2005). Considering the differences in mechanism and effect, knowledge of the sediment load changes is helpful in optimizing ecological restoration. However, study of sediment load changes between the separate ecological restoration periods has seldom been involved.

Studies have noted that streamflow decreased with the implementation of ecological restoration (Mu et al., 2007; Zhang et al., 2008; Zhao et al., 2014), whereas results regarding SSC-water discharge relationship were debatable. For instance, based on daily data, Xu (2002) and Liao et al. (2008) concluded that the frequency of hyperconcentrated flow (the main form of sediment transportation in the Loess Plateau) decreased with the implementation of soil conservation measures. Using annual data, Rustomji et al. (2008) showed that the mean annual SSC exhibited a statistically significant decreasing trend over time. Gao et al. (2012) detected monthly discharge-sediment relationship changes in the flood season and noted that the dynamic relationship between streamflow and sediment load changed. These consistent results indicate that ecological restoration has affected hydrological regimes in catchments. Conversely, Zheng et al. $(2007,2008)$ investigated interevent SSC-water discharge relationships in a small watershed. They noted that SSC-water discharge relationship was not changed by increasing vegetation coverage. The inconsistent SSC-water discharge relationship results are probably due to the spatialtemporal scale, specific landform features of the study areas, vegetation types and age, and the mixed nature of historic ecological management actions (Gao et al., 2012; Rustomji et al., 2008). The debatable results imply that further research is needed, especially in regard to the SSC-water discharge relationship.

We investigate the processes of sediment load changes and quantify the sediment yield reduction attributed to changes in both streamflow and SSC. Six sub-catchments nested in a representative basin within the Beiluo River basin were selected. In detail, we try to explore the following: (1) the trends of annual sediment yield and SSC in recent decades; (2) the processes of sediment yield changes between separate periods; and (3) the quantities of sediment yield reduction attributed to streamflow reduction and SSC-water discharge relationship changes.

\section{Data and methods}

\subsection{Study site}

The Beiluo River, with a drainage area of $26,905 \mathrm{~km}^{2}$ and a length of $680 \mathrm{~km}$, is one of the major coarse sand source tributaries of Yellow River (Yao et al., 2011). It is a tributary of the Weihe River and a secondary tributary of the Yellow River (Fig. 1) (Ran et al., 2000). Wind-deposited loess soils, developed during the Quaternary Period, cover the study area with a thickness of 50-200 m (Ran et al., 2000, 2012). The river basin is mostly semihumid, with a long-term mean annual precipitation of $514.2 \mathrm{~mm}$ and runoff depth of $32 \mathrm{~mm}$. It is one of the major coarse sediment source areas of the Yellow River, and the mean annual streamflow and sediment yield are $8.65 \times 10^{8} \mathrm{~m}^{3}$ and $8.65 \times 10^{7} \mathrm{t}$, respectively (Ran et al., 2000; Yao et al., 2011). The area, mean annual streamflow and sediment yields of the Beiluo River account for 3.57\%, 1.49\%, and 5.41\% of those of the Yellow River, respectively (Yao et al., 2011). Approximately $76.2 \%$ of the annual precipitation occurs during the May to September wet season, and $91.1 \%$ of total annual sediment yield was transported by floods (Ran et al., 2000). Extreme climate 


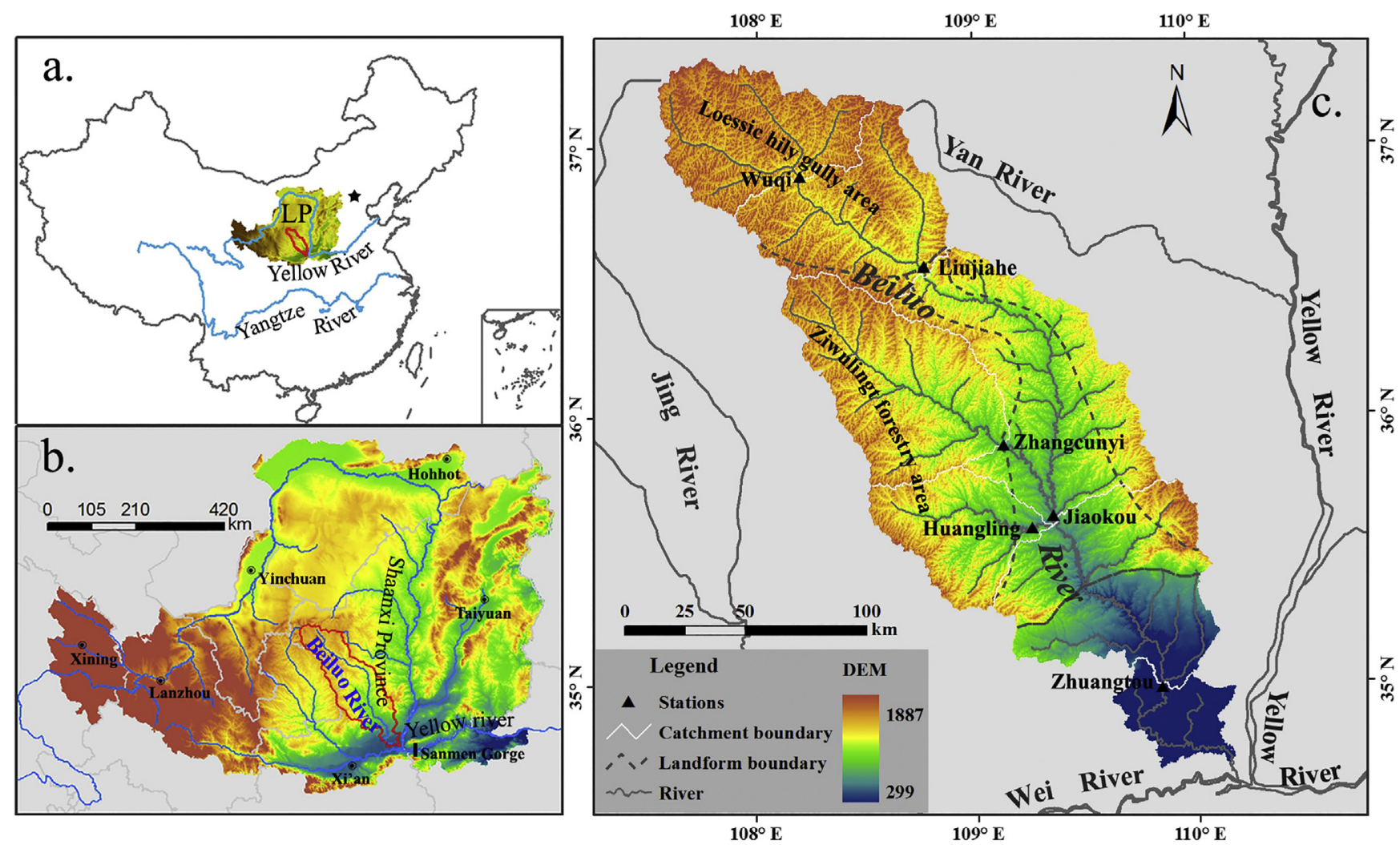

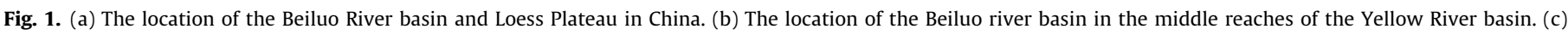
Location map of the Beiluo River basin with details of sub-catchments in the basin (Ran et al., 2012).

events happen occasionally in the area and are one of the most important factors in the fragile ecosystem. For instance, a daily SSC of $1060 \mathrm{~kg} \cdot \mathrm{m}^{-3}$, which was induced by an extreme precipitation event with a return period of over 1000 years, was measured on 31 August 1994 at the Wuqi station (Ran et al., 2000; Zhang et al., 2010). The streamflow on that day was 2.59 times the mean annual streamflow during 2003-2009, and the sediment yield on that day was equivalent to $10.6 \%$ of the total sediment yield between 1963 and 2009, excepting that day (Zhang et al., 2016).

Six stations were selected for this study, the details of which are shown in Table 1 (Ran et al., 2012). The area and streamflow of the catchment above Liujiahe account for $29.1 \%$ and $29.4 \%$, respectively, of the entire basin (above Zhuangtou), but its mean annual sediment yield accounts for $90.6 \%$ of the entire basin (1957-2009). As the annual sediment yield and SSC were plotted in Fig. 3, statistically significant correlations $(P<0.01)$ of sediment yield and SSC were identified between Wuqi/Liujiahe and Jiaokou/Zhuangtou (Ran et al., 2000, 2012; Yao et al., 2011). These indicate that the catchment above the Liujiahe station is the sediment source for the Beiluo River basin. In the 1950s, for- est coverage in the Loess Plateau was only 7.1\% (Cai, 2001). The catchments above the Zhangcunyi and Huangling stations are located in Ziwuling, which was the only place in the Loess Plateau where forest vegetation has been preserved throughout history. In these catchments, few ecological management actions (Table 1) and minimal human activities have affected the Loess Plateau. The sediment yield in the two catchments is below the soil loss tolerance, $500 \mathrm{t} \cdot \mathrm{km}^{-2} \cdot \mathrm{yr}^{-1}$. The streamflow of the catchment below Liujiahe and Zhangcunyi and above Zhuangtou accounts for $57 \%$ of the entire basin, with the area accounting for $52.2 \%$ (Ran et al., 2000). This indicates that the source areas of streamflow and sediment are distributed differently in the basin, a universal phenomenon of the Yellow River basin (Ran et al., 2000; Tang, 2004).

To reduce sediment load in the Yellow River, integrated soil conservation since the 1970s and the "Grain for Green" project since the 1990s have been implemented widely in the Beiluo River basin. Table 2 lists areas subjected to soil conservation measures in each sub-catchment. The annual streamflow and sediment yield decreased with increasing treated area, as seen from Fig. 2.

Table 1

Catchment characteristics and hydrologic records (Ran et al., 2012).

\begin{tabular}{|c|c|c|c|c|c|c|c|c|}
\hline \multirow[t]{2}{*}{ No. } & \multirow[t]{2}{*}{ Stations } & \multirow{2}{*}{$\begin{array}{l}\text { Area } \\
\left(\mathrm{km}^{2}\right)\end{array}$} & \multirow{2}{*}{$\begin{array}{l}\text { Streamflow } \\
\text { records }\end{array}$} & \multirow{2}{*}{$\begin{array}{l}\text { Sediment concentration } \\
\text { ranges }\left(\mathrm{m}^{3} / \mathrm{s}\right)\end{array}$} & \multicolumn{4}{|c|}{ Annual Average } \\
\hline & & & & & $\begin{array}{l}\text { Streamflow } \\
\left(\mathrm{mm} \cdot \mathrm{a}^{-1}\right)\end{array}$ & $\begin{array}{l}\text { Sediment yield } \\
\left(\mathrm{t} \cdot \mathrm{km}^{-2} \cdot \mathrm{a}^{-1}\right)\end{array}$ & $\begin{array}{l}\text { Sediment concentration } \\
\left(\mathrm{kg} \cdot \mathrm{m}^{-3}\right)\end{array}$ & $\begin{array}{l}\text { Vegetation } \\
\text { coverage (\%) }\end{array}$ \\
\hline 1 & Wuqi & 3408 & 1963-2009 & $0.01-41,831$ & 28.0 & 9822.7 & 295.3 & 32.5 \\
\hline 2 & Liujiahe & 7325 & 1959-2009 & $0.48-2560$ & 32.3 & 9397.9 & 248.5 & \\
\hline 3 & Zhangcunyi & 4715 & 1958-2009 & $0.026-202$ & 23.0 & 209.7 & 9.27 & 66.6 \\
\hline 4 & Huangling & 2266 & 1967-2009 & $0.008-234$ & 46.8 & 199.0 & 3.12 & \\
\hline 5 & Jiaokou & 17,180 & 1967-2009 & $0.30-1400$ & 25.9 & 4198.3 & 147.9 & 52.2 \\
\hline 6 & Zhuangtou & 25,654 & 1957-2009 & $0.67-1952$ & 32.3 & 2889.3 & 84.5 & 44.7 \\
\hline
\end{tabular}


Table 2

Percentage of cumulative area treated by ecological management actions during 1959-2006.

\begin{tabular}{|c|c|c|c|c|c|c|}
\hline \multirow[t]{2}{*}{ Corresponding stations } & \multirow[t]{2}{*}{ Year } & \multicolumn{4}{|c|}{ Ecological management actions } & \multirow[t]{2}{*}{ Total $(\%)$} \\
\hline & & Terrace $(\%)$ & Afforestation (\%) & Pasture (\%) & Sediment trapping dams (\%) & \\
\hline \multirow[t]{6}{*}{ Wuqi Liujiahe } & 1959 & 0.04 & 0.77 & 0.02 & 0.01 & 0.8 \\
\hline & 1969 & 0.52 & 2.43 & 0.19 & 0.15 & 3.3 \\
\hline & 1979 & 1.26 & 4.22 & 0.53 & 0.29 & 6.3 \\
\hline & 1989 & 1.98 & 8.14 & 2.47 & 0.29 & 12.9 \\
\hline & 1996 & 2.99 & 12.35 & 3.95 & 0.29 & 19.6 \\
\hline & 2006 & 3.88 & 22.14 & 10.06 & 0.29 & 36.4 \\
\hline \multirow[t]{6}{*}{ Zhangcunyi Huangling } & 1959 & 0.02 & 0.05 & 0.00 & 0.00 & 0.1 \\
\hline & 1969 & 0.18 & 0.16 & 0.01 & 0.01 & 0.4 \\
\hline & 1979 & 0.72 & 0.28 & 0.02 & 0.04 & 1.0 \\
\hline & 1989 & 0.69 & 0.53 & 0.08 & 0.05 & 1.4 \\
\hline & 1996 & 1.04 & 0.81 & 0.13 & 0.05 & 2.0 \\
\hline & 2006 & 1.35 & 0.96 & 0.17 & 0.05 & 2.5 \\
\hline \multirow[t]{6}{*}{ Jiaokou } & 1959 & 0.03 & 0.65 & 0.01 & 0.01 & 0.7 \\
\hline & 1969 & 0.40 & 2.04 & 0.11 & 0.17 & 2.7 \\
\hline & 1979 & 1.07 & 3.54 & 0.31 & 0.24 & 5.2 \\
\hline & 1989 & 1.56 & 6.83 & 1.43 & 0.24 & 10.1 \\
\hline & 1996 & 2.35 & 10.36 & 2.28 & 0.24 & 15.2 \\
\hline & 2006 & 3.04 & 18.57 & 5.79 & 0.24 & 27.6 \\
\hline \multirow[t]{6}{*}{ Zhuangtou } & 1959 & 0.03 & 0.44 & 0.01 & 0.01 & 0.5 \\
\hline & 1969 & 0.31 & 1.40 & 0.07 & 0.05 & 1.8 \\
\hline & 1979 & 0.76 & 2.43 & 0.21 & 0.12 & 3.5 \\
\hline & 1989 & 1.20 & 4.69 & 0.97 & 0.17 & 7.0 \\
\hline & 1999 & 4.77 & 11.80 & 1.75 & 0.17 & 18.5 \\
\hline & 2006 & 6.18 & 21.16 & 4.44 & 0.17 & 32.0 \\
\hline
\end{tabular}

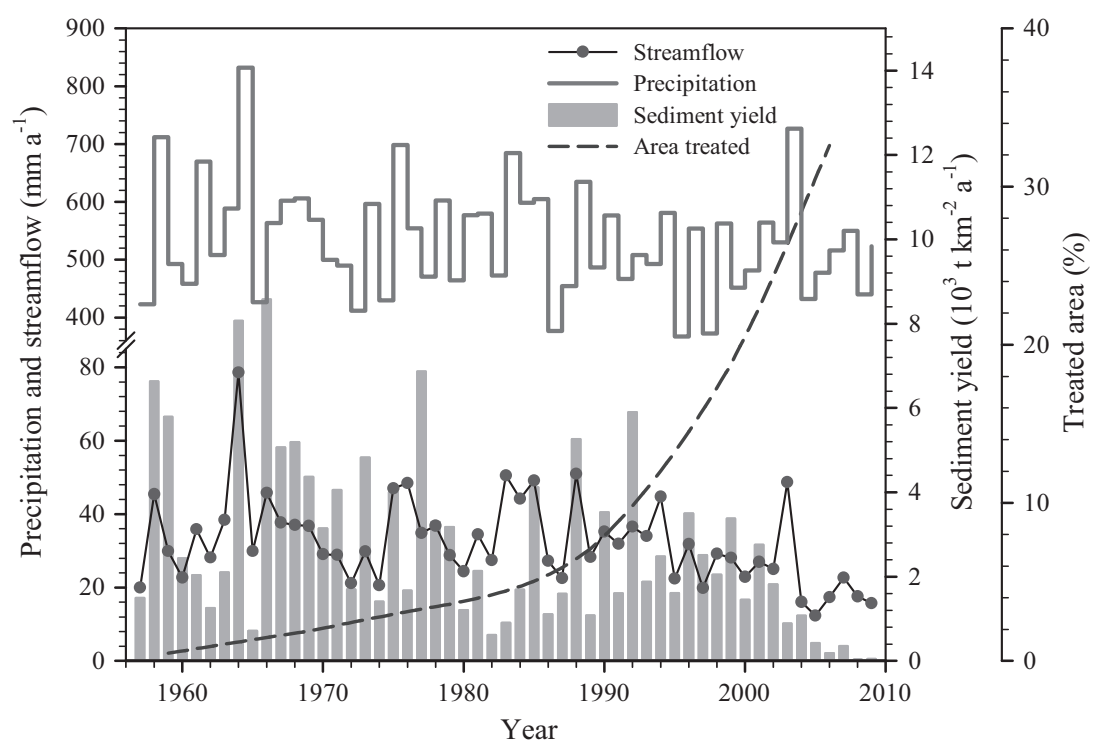

Fig. 2. Annual precipitation, streamflow, PET and the area affected by soil conservation measures for the Beiluohe (above the Zhuangtou station) catchment.

\subsection{Data}

Streamflow and SSC data were obtained from the Water Resources Committee of the Yellow River Conservancy Commission, Zhengzhou, China. Annual and monthly sediment data ware accumulated by daily sediment yield calculated from daily streamflow and SSC data. It should be noted that observations of SSC between December and March were not collected at the Wuqi, Liujiahe, Zhangcunyi and Huangling stations in the late $1990 \mathrm{~s}$ because sediment yields during those four months account for $<5 \%$ of annual sediment yields. Daily precipitation data were obtained from the State Meteorology Bureau (http://cdc.nmic.cn/ home.do). Annual precipitation was calculated using daily data. ArcGIS 9.3 was used to interpolate annual precipitation data for each catchment, and the Kriging technique (spherical semivariogram model) was used for data interpolation (Oliver and Webster, 1990).

\subsection{Methods}

The Mann-Kendall (M-K) rank correlation coefficient (Kendall, 1975; Mann, 1945) is commonly used to assess the significance of trends in hydro-meteorological time series and has been used in this study. The Mann-Kendall test statistic (S) is given by

$S=\sum_{k=1}^{n-1} \sum_{j=k+1}^{n} \operatorname{sign}\left(x_{j}-x_{k}\right), \quad k<j<n$ 


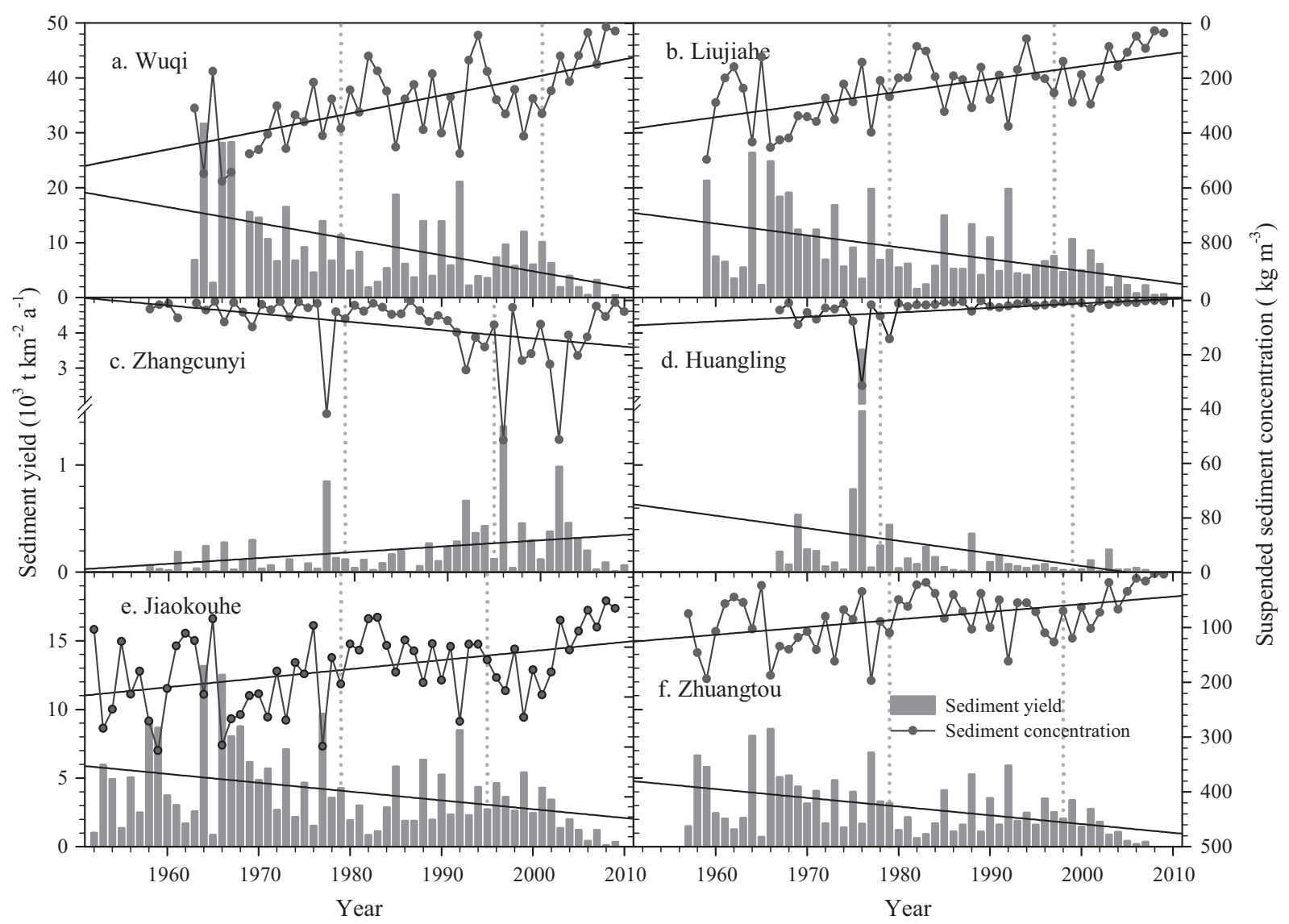

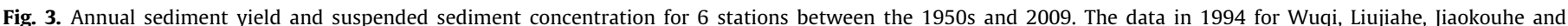

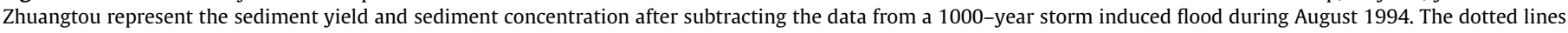
represent the change point years during the study period.

where $n$ is the dataset record length and $x_{j}$ and $x_{k}$ are sequential data values. When $S$ is positive, a positive trend is present and vice versa.

The nonparametric median-based linear model method proposed by Sen (1968) has been used to fit trend slopes, $\beta$, to the data:

$\beta=\operatorname{Median}\left[\frac{x_{j}-x_{k}}{j-k}\right] \quad$ for all $k<j$

where $1<k<j<n$. $\beta$ is median of all possible combinations of pairs for the entire dataset.

The nonparametric method developed by Pettitt (1979) was applied to detect the change point using the Mann-Whitney statistic $U_{t, N}$. The $U_{t, N}$ is used to verify whether two samples $x_{1}, \ldots, x_{t}$ and $x_{t+1}, \ldots, x_{N}$ are from the same population. The test statistic $U_{t, N}$ is given by

$U_{t-1, N}=U_{t-1, N}+\sum_{j=1}^{N} \operatorname{sign}\left(x_{t}-x_{j}\right)$ for $t=2, \ldots, n$

The test statistic counts the number of times a member of the first sample exceeds a member of the second sample. The null hypothesis of the Pettitt test is the absence of a change point. The statistic $k(t)$ and the associated probabilities used in the significance testing are given as

$k(t)=\max _{1 \leqslant t \leqslant N}\left|U_{t, N}\right|$

$p \cong 2 \exp \left\{-6\left(K_{n}^{2}\right) /\left(N^{3}+N^{2}\right)\right\}$
Directional change and the trend of daily and annual data were determined by applying the nonparametric Mann-Kendall trend test, and the magnitude of the trend was detected by Sen's slope.

An incremental percentiles method on an annual basis was used to obtain the long-term daily series. For the proportion of trend comparison in different percentiles, daily series were normalized before applying the M-K test and Sen's slope estimation by equation (Du et al., 2013)

$X_{i}^{\prime}=\left(X_{i}-X_{\min }\right) /\left(X_{\max }-X_{\min }\right)$

Although the Mann-Kendall test does not require that the distribution be normalized, the presence of an autocorrelation in the dataset violates the independence assumption. In this case, the effective degree of freedom will be less than the number of observations. Consequently, if the autocorrelation is not taken into account, the resulting trend will be spurious (Wilcox et al., 2008). So we performed the autocorrelation detecting before trend testing. The significance of the first-order autocorrelation was judged using Durbin-Watson statistics at a 0.05 significance level (Bowerman and O'Connell, 1979). If an autocorrelation was not present, trend analysis was performed directly. Otherwise, the autocorrelation was removed to construct an independent data series using the Cochrane-Orcutt procedure (Cochrane and Orcutt, 1949):

$X_{i}^{\prime}=X_{i}-\rho X_{i-1}$

where $X_{i}^{\prime}$ is a datum of the transformed time series values, $X_{i}$ the original time series value, and $\rho$ the estimated serial correlation. 
After removing the autocorrelation, trend analysis was performed on the transformed series.

\section{Results}

\subsection{Trends of annual sediment yield and SSC}

As shown in Table 3, the Mann-Kendall test identified significantly negative trends for 5 stations and a positive trend for the Zhangcunyi station in both annual sediment yield and SSC $(\mathrm{P}<0.01)$. The decreasing rate of annual sediment yield varied from $-4 \mathrm{t} \cdot \mathrm{km}^{-2} \cdot \mathrm{yr}^{-1}$ in subcatchments with forest cover to $-214 \mathrm{t} \cdot \mathrm{km}^{-2} \cdot \mathrm{yr}^{-1}$ in the sediment source area with sparse shrub and grass vegetation. For the entire Beiluo River basin (Zhuangtou station), the trend of sediment yield was $-57 \mathrm{t} \cdot \mathrm{km}^{-2} \cdot \mathrm{yr}^{-1}$. The trends of SSC varied from -0.08 to $-6.77 \mathrm{~kg} \cdot \mathrm{m}^{-3} \cdot \mathrm{yr}^{-1}$, and the trend of SSC was $-1.30 \mathrm{~kg} \cdot \mathrm{m}^{-3} \cdot \mathrm{yr}^{-1}$ in the entire basin. Using Pettitt's method, the annual sediment yield exhibits two different changing periods; thus, two points were identified for each annual sediment series. As shown in Table 3, the first change points at all stations were consistently detected between 1977 and 1979, and the second change point occurred between 1988 and 2001. These change points are concurrent with the ecological restoration in recent decades, which supports the investigation of the effects on sediment yield changes. Using these change points, the sediment yield and SSC series were divided into the baseline period $\left(P_{1}\right)$, soil conservation period $\left(P_{2}\right)$ and "Grain for Green" period $\left(P_{3}\right)$.

\subsection{Changes in daily sediment yield and SSC}

Given that both sediment yield and SSC were detected with significant trends, we examined the daily sediment yield and SSC trends in more detail. The sediment yield and SSC data were aggregated in two ways, including by day and by "event". To obtain a long-term daily data series, the data in each year were sorted in descending order, and data within the same percentile of exceedance were selected. The obtained daily percentile series was sorted by year; the series are described as daily data (daily sediment yield, daily streamflow, daily SSC) below.

\subsubsection{Trend of daily sediment yield and SSC}

Given the mixed nature of ecological restoration measures, the streamflow, sediment yield and SSC changes represented by the trends of the daily series are likely to reflect the combined effects. For comparison, each series was normalized by Eq. (6), ranging from 0 to 100 . These normalized daily series were analyzed by the M-K test and Sen's slope test, and the results are plotted in Fig. 4. The trends of the normalized daily series reflect the proportional changes of the observed data of various magnitudes over the past 60 years. As shown in Fig. 4, significant trends were identified in various daily series for sediment yield, SSC and streamflow. Notably, the high daily SSC (1-5\% in percentile) reductions at 5 stations (excepting the increase at Zhangcunyi) are particularly significant, although the trends of the extremes (top 1 percentile) are comparatively smaller. Their trends are higher than those in moderate and low SSC (10-100\%). The results of trend analysis of daily streamflow (especially high flow) are not consistent in upstream (Fig. 4a-d). The trends of daily streamflow in high flow are variable among the 4 upstream stations, and thus resulted in variable trends of daily sediment yield among stations. However, consistent results were observed for the 2 downstream stations, Jiaokouhe and Zhuangtou. For the entire basin, high sediment yield, SSC and high flow (1-5\%) significantly decreased, and their trends are generally higher than those in moderate and lower percentiles (Fig. 4e and 4f). This result means that the principal part of sediment yield-the hyperconcentrated flow-could be effectively controlled by ecological restoration over time. The low streamflow, SSC and sediment yield (80-100\%) changes were not consistent at the Jiaokouhe and Zhuangtou stations. But sediment yield in the $80-100 \%$ percentiles accounted for only $1.46 \%$ of sediment yield in the entire basin from 1957-2009, indicating that changes in these percentiles have little influence on total sediment yield changes.

\subsubsection{Sediment yield and SSC changes during three periods}

To gain additional perspective on the magnitude of sediment yield reduction during the separate periods, the sediment yield duration curves were plotted in $\log -\log$ form (Fig. 5). As shown in Fig. $5 \mathrm{a}$ and c, the reductions in high sediment yield (top 5 percentiles) are most apparent during $P_{2}$, while little difference can be observed in moderate and low sediment yield (10-100\%). However, the sediment yield was dramatically reduced in all percentiles during the "Grain for Green" period. For the only station with a positive trend in sediment yield, Zhangcunyi, the total sediment yield increased mainly due to increasing high sediment load (top 5 percentiles, Fig. 5b).

Generally, the annual top 5 daily sediment loads have been the focus of river sediment research because they account for the majority (e.g., >90\%) of total sediment load in a year (Rustomji et al., 2008). The top 5 daily sediment loads in each year and their corresponding streamflow and SSC were selected from the observed daily data series. The proportion of the annual sediment load transported in these 5 days of each year was also calculated. By the two sample $t$-test, the means of the sediment load and the corresponding streamflow, SSC and proportion of total load for the top 5 days among the 3 periods were examined, and the results are shown in Fig. 6.

Statistically significant reductions were identified in sediment yield, streamflow and SSC in the 5 maximum load days at Wuqi and Liujiahe, the sediment source area (Fig. 6a-c). Significant reductions in SSC were also identified at the downstream stations of Jiaokouhe and Zhuangtou (Fig. 6b). Moreover, the differences in streamflow in the 5 maximum days between stations have diminished (Fig. 6a). The findings indicate that the maximum sediment

Table 3

Summary of trend analysis by Mann-Kendall nonparametric test and Pettitt's test for annual sediment yield and annual sediment concentration in each catchment.

\begin{tabular}{|c|c|c|c|c|c|c|c|c|c|c|c|c|}
\hline \multirow[t]{3}{*}{ Stations } & \multicolumn{5}{|c|}{ Annual sediment yield } & \multicolumn{5}{|c|}{ Annual sediment concentration } & \multirow{3}{*}{$\begin{array}{l}\text { Change point by soil } \\
\text { conservation }\end{array}$} & \multirow{3}{*}{$\begin{array}{l}\text { Change point by } \\
\text { "Grain for green" }\end{array}$} \\
\hline & \multicolumn{2}{|c|}{ Correlation } & \multicolumn{2}{|c|}{ Mann-kendall } & \multirow{2}{*}{$\begin{array}{l}\text { Sen } \\
\beta \\
\left(10^{2} \mathrm{t} \cdot \mathrm{km}^{-2} \cdot \mathrm{a}^{-1}\right)\end{array}$} & \multicolumn{2}{|c|}{ Correlation } & \multicolumn{2}{|c|}{ Mann-kendall } & \multirow{2}{*}{$\begin{array}{l}\text { Sen } \\
\beta \\
\left(\mathrm{kg} \cdot \mathrm{m}^{-3} \cdot \mathrm{a}^{-1}\right)\end{array}$} & & \\
\hline & Lag 1 & $P$ & $Z$ & $P$ & & Lag 1 & $P$ & $Z$ & $P$ & & & \\
\hline Wuqi & -0.08 & 0.31 & -3.62 & $<0.001$ & -2.14 & 0.16 & 0.46 & -4.11 & $<0.001$ & -6.77 & 1979[1979] & $2001[2001]$ \\
\hline Liujiahe & -0.03 & 0.53 & -3.69 & $<0.001$ & -1.79 & 0.22 & 0.51 & -4.16 & $<0.001$ & -4.71 & 1979[1979] & 1997[1994] \\
\hline Zhangcunyi & 0.09 & 0.79 & 2.63 & 0.0085 & 0.03 & 0.18 & 0.59 & 3.53 & $<0.001$ & 0.21 & 1977[1976] & $1990[1989]$ \\
\hline Huangling & 0.14 & 0.44 & -3.96 & $<0.001$ & -0.04 & 0.16 & 0.75 & -4.46 & $<0.001$ & -0.08 & 1979[1979] & $1988[1988]$ \\
\hline Jiaokou & -0.04 & 0.61 & -2.68 & 0.0073 & -0.54 & 0.15 & 0.40 & -2.59 & 0.0096 & -1.78 & 1979[1979] & 1995[2001] \\
\hline Zhuangtou & 0.00 & 0.44 & -3.46 & $<0.001$ & -0.57 & 0.17 & 0.40 & -2.85 & 0.0044 & -1.30 & 1978[1979] & $1999[2001]$ \\
\hline
\end{tabular}




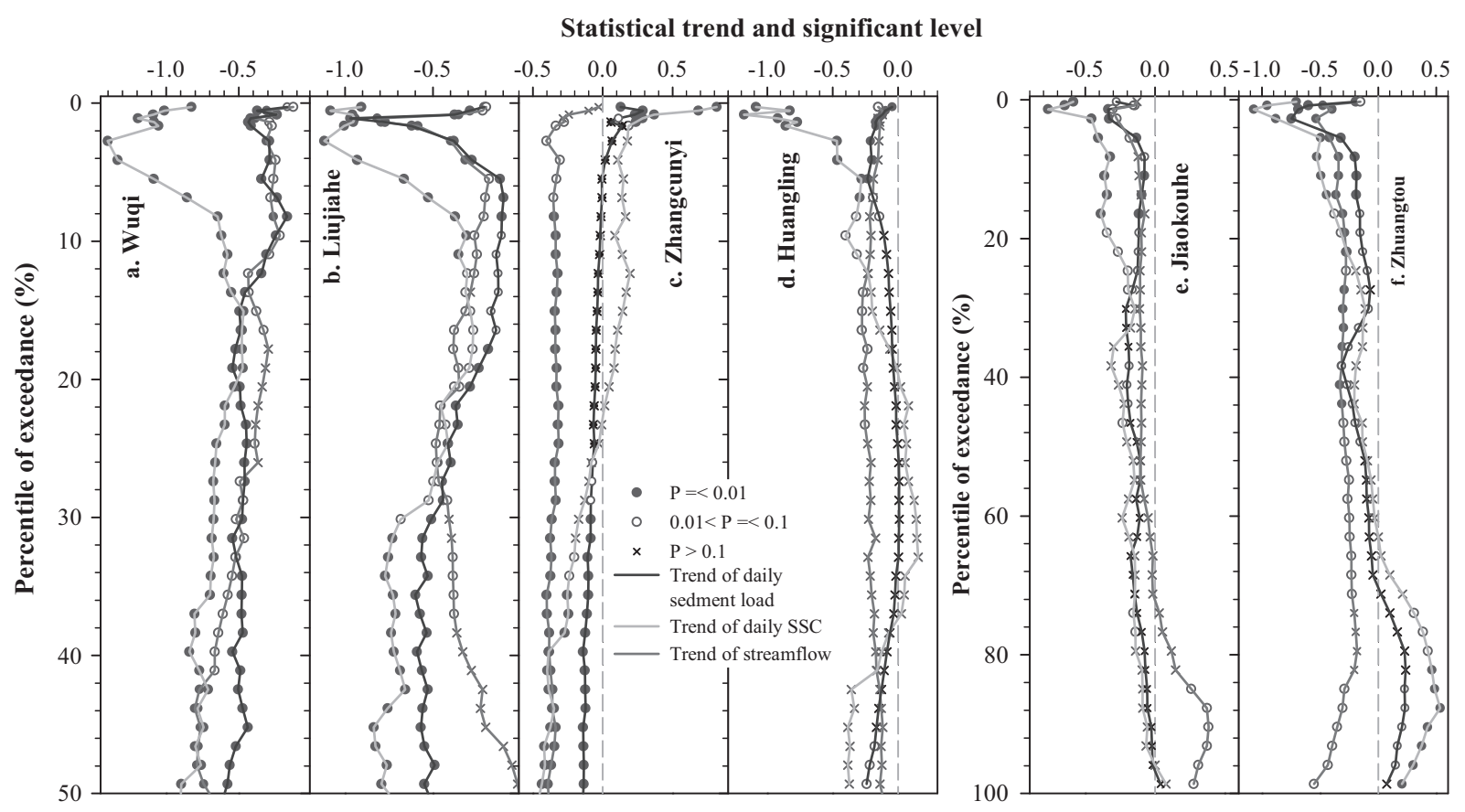

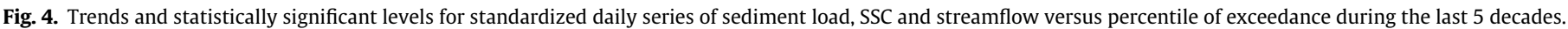
The horizontal axis is trend slope, $\beta$, and the signs (dots, circles and crosses) denote different significant levels.

load can be controlled and that it has been altered by progressive ecological restoration. Moreover, the extreme SSC and streamflow (top 1 percentile) changes are not as large as those in high SSC and flow (1-5\%, Fig. 4). As a result, the proportion of sediment load in the top 5 days did not decrease but tended to increase (Fig. 6d).

\subsection{Rainfall event-induced sediment yield and SSC}

Previous research suggested that sediment transport in the Loess Plateau is strongly event-driven (Xu, 1994; Zhang et al., 1997, 2008), indicating that the sediment yield examined above may potentially be masking important event-based details. To explore this suggestion, event-scale hydrological regimes were detected on the basis of rainfall events. By definition, rainfall was considered to belong to one event unless separated from the next rainfall by at least 2 no-rain days. Using daily precipitation data, event hydrological data at the Wuqi station were calculated and shown versus the return period in Fig. 7.

As shown in Fig. 7a and c, the event streamflow and sediment load with the same return period/frequency dramatically decreased. As shown in Fig. 7b, the curves of event SSC versus return period are "S" shaped with a "roof," i.e., a limit on the highest SSC, but the values decrease over time. For instance, the 1000-year storm event in 1994 was the strongest precipitation event in the period from 1957 to 2009 , but the SSC driven by the storm was still lower than much of those in $P_{1}$. This result is evidence that ecological management has reduced the mobility of sediment within the catchment. Moreover, the maximum event sediment yield and SSC decreased significantly, whereas no significant trend was identified for annual maximum rainfall (Fig. 7d). The finding implies that the rainfall-streamflow, rainfall-SSC and rainfall-sediment load dynamics have changed in the context of the continuously underlying surface changed by ecological restoration. The event SSC has decreased over time (Fig. 7b), except that event SSC with moderate return periods (0.1-0.3 years) increased during $P_{2}$. The increased SSC may be due to the remobilization of in-channel sediment stores after the sediment-trapping dams were destroyed.

\subsection{SSC-water discharge relationship changes}

Thus far, it has been demonstrated that, on annual, daily and event timescales, there have been significant reductions in sediment yield for 5 out of 6 sub-catchments. Moreover, the individual changes in streamflow, sediment yield and SSC on the daily timescale show that the changes irregularly varied with the magnitude (i.e., percentiles in Fig. 4) of these variables. When explaining these findings, ambiguity exists between two scenarios, as (1) the significant reduction of sediment load can be attributed to significant changes in both streamflow and SSC, and (2) the significant reduction of sediment load is associated only with a significant change in streamflow.

The SSC is positively related to discharge at the long-term scale (Hicks et al., 2000; Rustomji et al., 2008). It implies that sediment yield changes can be expressed by the distribution of SSC versus streamflow. The daily sediment load/SSC versus streamflow are plotted in Fig. $8 \mathrm{a} / \mathrm{d}\left(P_{1}\right)$, b/e $\left(P_{3}\right)$. For both $P_{1}$ and $P_{3}$, the mean and median sediment load and SSC for 40 equally spaced discharge classes (defined on the log-discharge scale) have been calculated. As noted by Rustomji et al. (2008), these curves represent a form of sediment rating. If the ecological management actions had reduced the capacity for sediment to be mobilized in the landscape, a reduction in the $\mathrm{SSC} /$ sediment loads at a given streamflow would be expected in the later period. For comparison, the results obtained from Fig. 8a and b/d and e are plotted in Fig. 8c/f. As shown in Fig. $8 \mathrm{c}$ and $\mathrm{f}$, the curves of the means and medians showed that streamflow in $P_{3}$ tended to exhibit lower magnitudes. Both the medians and means of sediment load in $P_{3}$ were lower at streamflow intervals $>50 \times 10^{-3} \mathrm{~mm} \cdot \mathrm{d}^{-1}$. However, the medians of sediment load at moderate streamflow $\left(4-50 \times 10^{-3} \mathrm{~mm} \cdot \mathrm{d}^{-1}\right)$ and the means at streamflow intervals $7 \times 10^{-3}-12 \times 10^{-3} \mathrm{~mm} \cdot \mathrm{d}^{-1}$ were higher. Since high sediment load account for majority of total sediment load, the much lower value of high sediment load/SSC indicates that sediment load/SSC-water discharge relationships have changed. The changes in means and medians in SSC are similar to those in sediment load. Given that the means and medians 

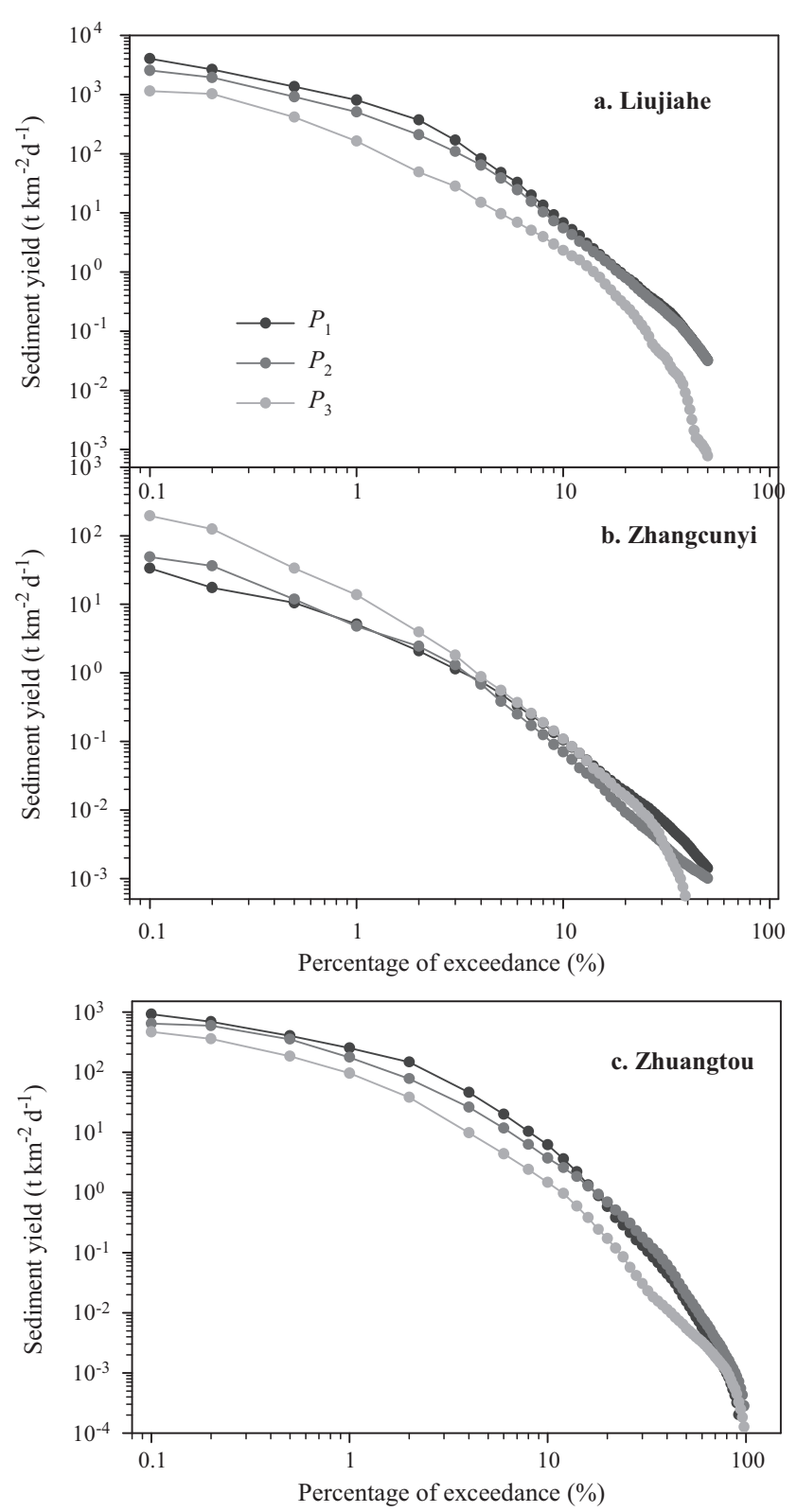

Fig. 5. Comparison of daily sediment yield duration curves for three periods for (a) the Liujiahe station, (b) the Zhangcunyi station at percentiles $\leqslant 50 \%$, and (c) the entire basin represented at the Zhuangtou station.

in streamflow classes are generally important in detecting changes in the sediment load and SSC-water discharge relationship, it essentially appears as though the frequency/probability is equally important. The probability of streamflow distributed in the 40 equally spaced discharge classes was plotted in Fig. 8. As shown in Fig. $8 \mathrm{c}$ and f, probability distribution curves for streamflow are different between $P_{1}$ and $P_{3}$. In detail, the probability distribution of streamflow shifted towards lower magnitudes. The findings exhibited that both streamflow and the sediment load/SSC-water discharge relationship essentially changed, and, consequently, scenario (2) is rejected.

\subsection{Streamflow and SSC changes contributed to sediment yield changes}

Table 4 examines the correlations between percentage of the area treated (by the four main management actions, including the total treated area) and the variations in annual sediment yield for the 6 sub-catchments. Except for the increased sediment at the Zhangcunyi station, 17 out of 25 management actions at sites were identified $(\mathrm{P}<0.05)$; however, only 4 management actions at sites had insignificant correlation with $\mathrm{P}>0.1$. The significant correlations between ecological management actions and sediment load indicate that ecological restoration indeed resulted in sediment yield decrease, as one of the alternative factors.

We have demonstrated that the sediment yield was reduced by decreasing streamflow and SSC. However, the quantities of sediment yield reduction attributed to streamflow and SSC changes remain unknown. To explore this question, a method based on the probability distribution of the SSC-water discharge relationship was developed. Based on fractal theory, the steps of the approach are as follows:

Generally, as shown in Figs. 8d-e and 9, the mean annual sediment load $(\Phi)$ over a long period ( $N$ years) with data series length $l$ divided into $n$ discharge classes (defined on the log-discharge scale) can be calculated by the equation

$\Phi=\frac{1}{N} \sum_{i=1}^{n} \sum_{j=1}^{m} Q_{i j} \cdot s_{i j}, \quad 1 \leqslant \mathrm{n} \leqslant l$

where $Q_{i j}$ is one of daily streamflow and $s_{i j}$ is the corresponding SSC, respectively, in discharge class $i ; \sum_{j=1}^{m} Q_{i j} \cdot s_{i j}$ is the total sediment yields in a discharge class $i$.

As shown in Fig. 9, $\sum_{j=1}^{m} Q_{i j} \cdot s_{i j}$ could be calculated by the average streamflow $Q_{i}$, average SSC $\bar{s}_{i}$ and streamflow frequency $F_{i}$; then the mean annual sediment yield $(\Phi)$ in Eq. (8) can be translated into

$\Phi=\frac{1}{N} \sum_{i=1}^{n} Q_{i} \cdot \bar{s}_{i} \cdot F_{i}=\sum_{i=1}^{n} Q_{i} \cdot \bar{s}_{i} \cdot f_{i}$

where $f_{i}$ is mean annual frequency of daily sediment yields in discharge class $i$. Then, the changes in mean annual sediment yields in two periods can be calculated by

$\Delta \Phi=\sum_{i=1}^{n} Q_{i} \cdot \bar{s}_{i}^{\text {pre }} \cdot f_{i}^{\text {pre }}-\sum_{i=1}^{n} Q_{i} \cdot \bar{s}_{i}^{\text {after }} \cdot f_{i}^{\text {after }}$

where pre and after indicating data of former period and later period, respectively.

The equation can be translated into

$$
\begin{gathered}
\Delta \Phi=\sum_{i=1}^{n}\left(Q_{i} \cdot \bar{s}_{i}^{\text {pre }} \cdot f_{i}^{\text {pre }}-Q_{i} \cdot \bar{s}_{i}^{\text {after }} \cdot f_{i}^{\text {after }}-Q_{i} \cdot \bar{s}_{i}^{\text {pre }} \cdot f_{i}^{\text {after }}+Q_{i} \cdot \bar{s}_{i}^{\text {pre }} \cdot f_{i}^{\text {after }}\right) \\
=\sum_{i=1}^{n}\left(Q_{i}\left(f_{i}^{\text {pre }}-f_{i}^{a f t e r}\right) \bar{s}_{i}^{\text {pre }}+Q_{i} \cdot f_{i}^{a f t e r}\left(\bar{s}_{i}^{\text {pre }}-\bar{s}_{i}^{\text {after }}\right)\right)
\end{gathered}
$$

For two series of separate periods in a basin, the streamflow changes are actually the differences in probability versus discharge; the sediment changes due to streamflow changes, $\Delta \Phi^{\text {Runoff }}$ and changes in SSC, $\Delta \Phi^{S S C}$ are obtained by Eq. (10b)

$$
\begin{gathered}
\Delta \Phi^{\text {Runoff }}=\sum_{i=1}^{n} Q_{i}\left(f_{i}^{\text {pre }}-f_{i}^{\text {after }}\right) \bar{S}_{i}^{\text {pre }} \\
\Delta \Phi^{S S C}=\sum_{i=1}^{n} Q_{i} \cdot f_{i}^{\text {after }}\left(\bar{S}_{i}^{\text {pre }}-\bar{S}_{i}^{\text {after }}\right)
\end{gathered}
$$

Then, the proportion of sediment load changes attributed to changes in SSC can be calculated, expressed as $P_{\text {calc }}\left(\Delta \Phi^{S S C}\right)$. Obviously, the $P_{\text {calc }}\left(\Delta \Phi^{S S C}\right)$ will change with changes in spaced discharge classes. Therefore, the $P_{\text {calc }}\left(\Delta \Phi^{S S C}\right)$ is indeed a function of the discharge classes $n$, expressed as 

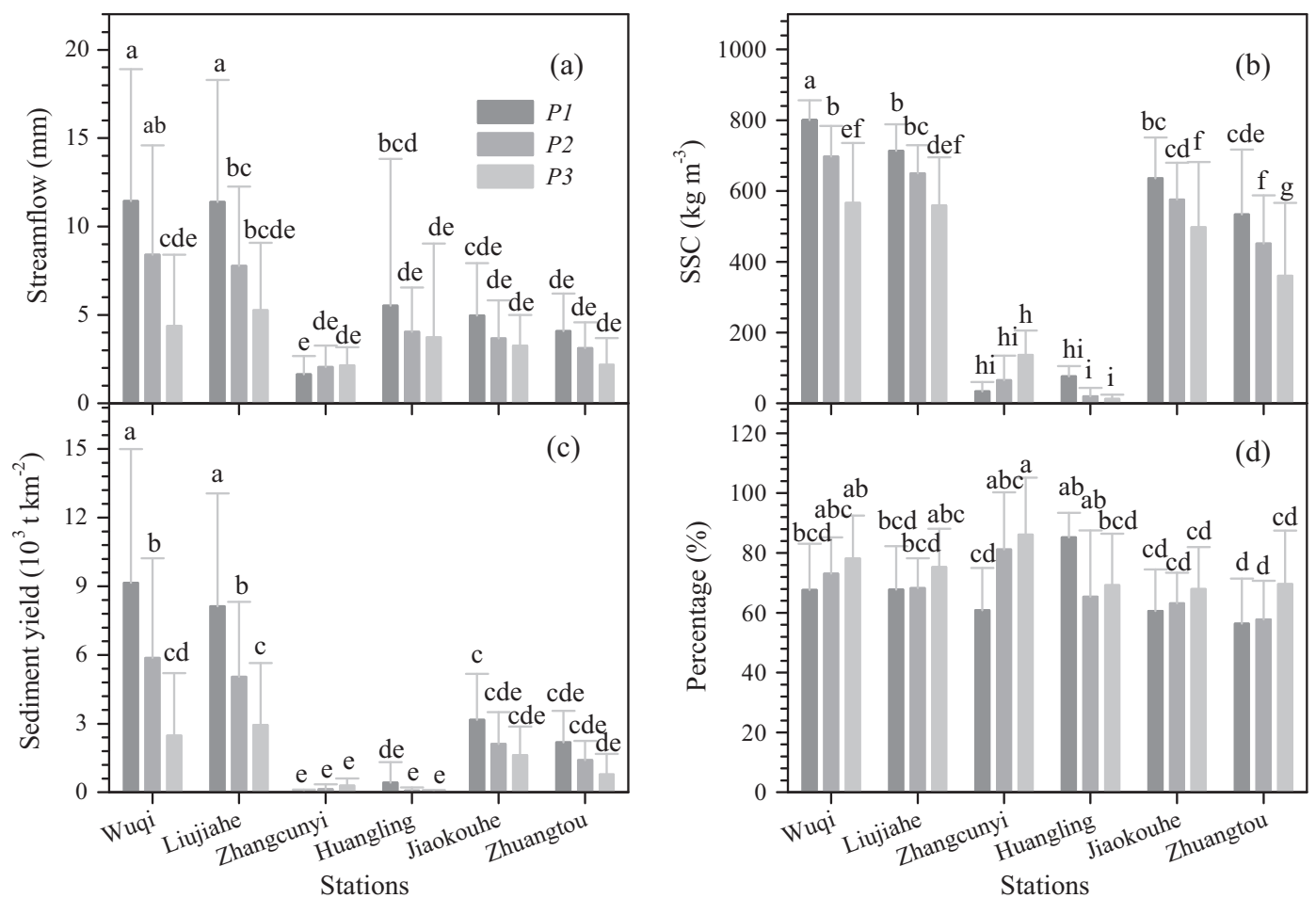

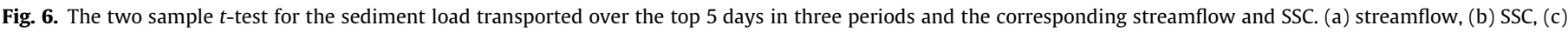
sediment yield and (d) the proportion of annual sediment load transported in the top 5 days within each year (the values are means \pm SD).
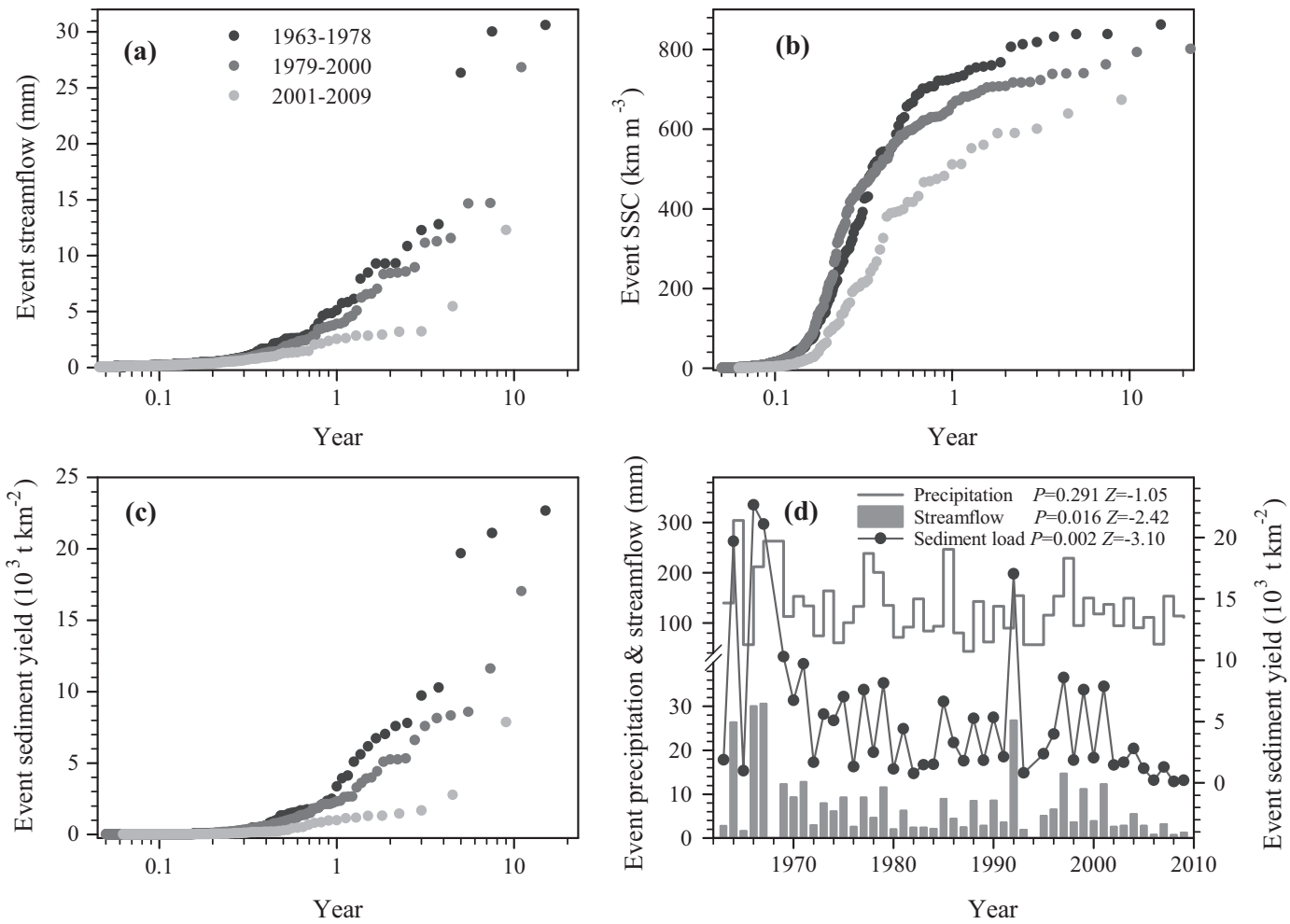

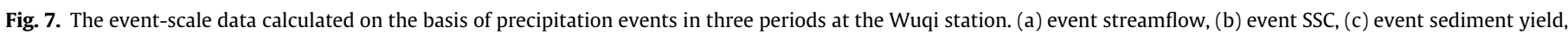
and (d) the annual highest event for streamflow, sediment yield and SSC and their trends from 1963 to 2009.

$P_{\text {calc }}\left(\Delta \Phi^{S S C}\right)=F(n)$

As shown in Fig. 9, the $F(n)$ varies with discharge class changes over the interval $[1, \infty]$. It decreases sharply as $n$ increases, then increases slightly to a maximum with discharge classes $n_{T}$ and then decreases slowly and converges to 0 . That is

$$
F(n \rightarrow 1) \rightarrow Q^{\text {pre }} / Q^{\text {after }} \quad F(n \rightarrow \infty) \rightarrow 0 \quad F\left(n \rightarrow n_{T}\right) \rightarrow F\left(n_{T}\right)
$$



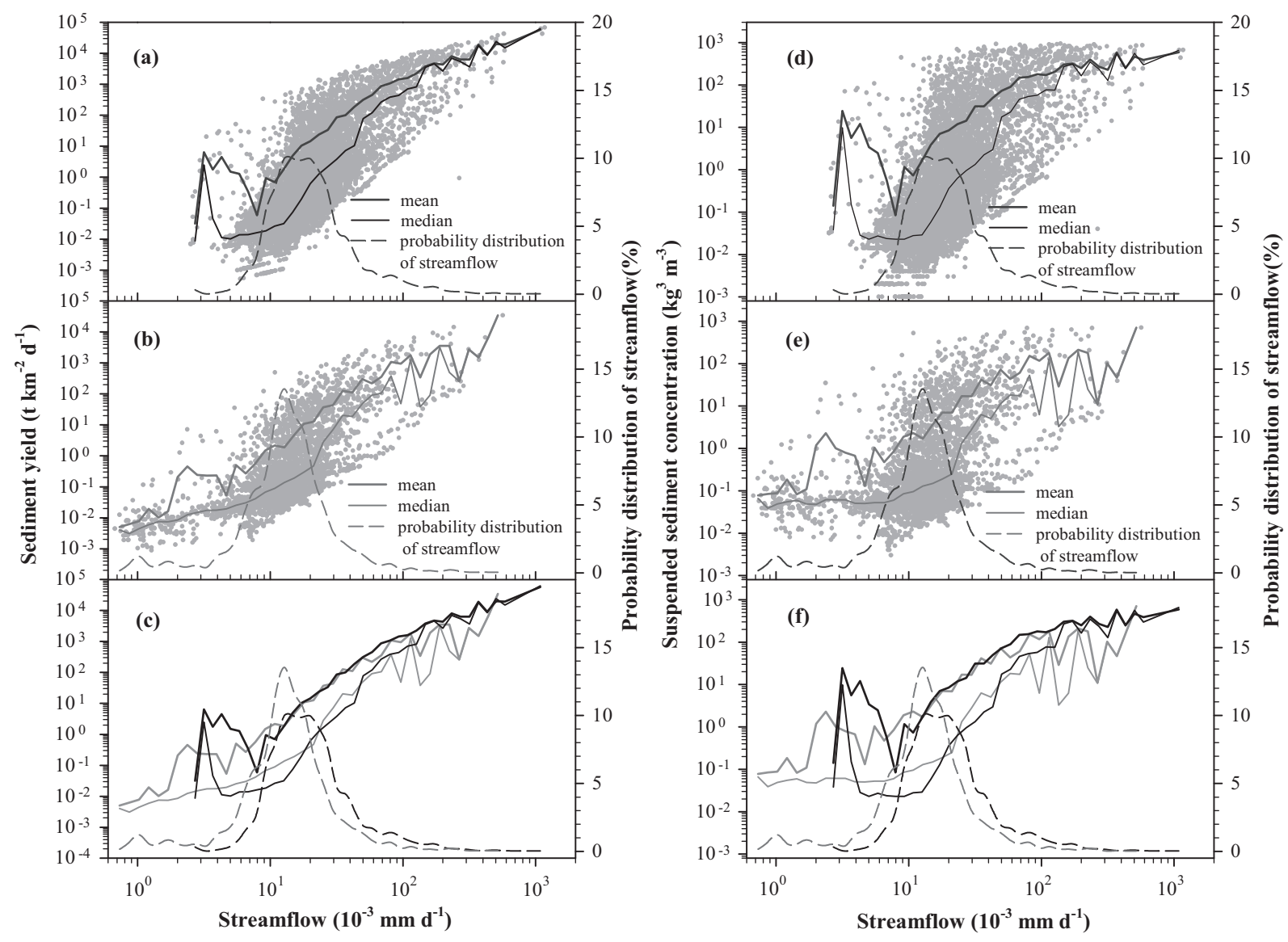

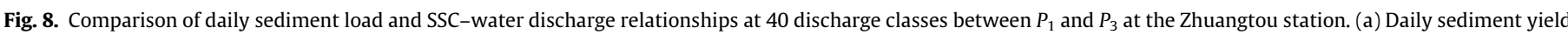

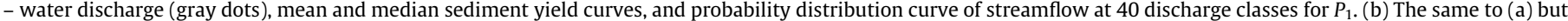

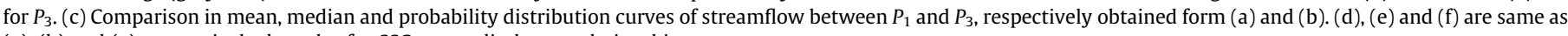
(a), (b) and (c), respectively, but plot for SSC-water discharge relationships.

Table 4

Statistical significance of correlation between sediment yields and soil conservation treated areas.

\begin{tabular}{|c|c|c|c|c|c|c|c|c|c|c|}
\hline \multirow[t]{2}{*}{ Stations } & \multicolumn{2}{|c|}{ Terrace } & \multicolumn{2}{|c|}{ Afforestation } & \multicolumn{2}{|c|}{ Pasture } & \multicolumn{2}{|c|}{$\begin{array}{l}\text { Sediment trapping } \\
\text { dams }\end{array}$} & \multicolumn{2}{|l|}{ Total } \\
\hline & Corr. & $P$ & Corr. & $P$ & Corr. & $P$ & Corr. & $P$ & Corr. & $P$ \\
\hline Wuqi & -0.93 & 0.02 & -0.89 & 0.04 & -0.81 & 0.10 & -0.97 & 0.01 & -0.88 & $<0.01$ \\
\hline Liujiahe & -0.95 & 0.01 & -0.92 & 0.03 & -0.84 & 0.07 & -1.00 & $<0.01$ & -0.91 & $<0.01$ \\
\hline Zhangcunyi & 0.49 & 0.40 & 0.69 & 0.20 & 0.73 & 0.16 & 0.49 & 0.40 & 0.67 & 0.21 \\
\hline Huangling & -0.90 & 0.04 & -0.80 & 0.11 & -0.70 & 0.19 & -0.93 & 0.02 & -0.82 & 0.09 \\
\hline Jiaokou & -0.93 & 0.02 & -0.85 & 0.07 & -0.76 & 0.14 & -0.98 & $<0.01$ & -0.85 & 0.07 \\
\hline Zhuangtou & -0.82 & 0.05 & -0.86 & 0.03 & -0.88 & 0.02 & -0.92 & 0.01 & -0.86 & 0.03 \\
\hline
\end{tabular}

where $Q^{\text {pre }}$ and $Q^{\text {after }}$ are mean annual streamflow in former and later periods, respectively. When $n=1$, sediment load reductions are categorized as changing in total streamflow and average SSC, $F(1)=Q^{\text {pre }} / Q^{\text {after }}$. When $n$ approaches $\infty$, they are all categorized as changing in streamflow. Obviously, these two points are at the maximum calculation errors, indicating that they are inappropriate discharge classes. The calculation error decreases as $n$ approaches $n_{T}$ from either side. The $F\left(n_{T}\right)$ (Fig. 9) is the maximum with minimal error that approximately equals the proportional reduction attributed to SSC change, $P\left(\Delta \Phi^{S S C}\right)$. Accordingly, $F\left(n_{T}\right)$ is the approximate value of $P\left(\Delta \Phi^{S S C}\right)$. Thus, the proportion of sediment load reduction attributed to changes in SSC is obtained: $P\left(\Delta \Phi^{\mathrm{SSC}}\right) \approx F\left(n_{T}\right)$.

Using Eqs. (11) and (12), the changes in mean annual sediment yield attributed to SSC in $P_{2}$ and $P_{3}$ were estimated. The mean annual sediment loads in 5 sub-catchments have decreased contin- uously during the last 5 decades. As shown in Table 5, the proportions of sediment load reduction attributed to SSC changes varied from $8.5 \%$ to $56.8 \%$ during $P_{2}$ and from $15.0 \%$ to $51.7 \%$ during $P_{3}$. Although no obvious increase in proportion was observed between $P_{2}$ and $P_{3}$, the increased absolute values are much more evident. Basin-wide, the mean annual sediment yield at the Zhuangtou station during $P_{1}$ is $3876 \mathrm{t} \cdot \mathrm{km}^{-2} \cdot \mathrm{yr}^{-1}$, but it was $2438 \mathrm{t} \cdot \mathrm{km}^{-2} \cdot \mathrm{yr}^{-1}$ during $P_{2}$ and only $1127 \mathrm{t} \cdot \mathrm{km}^{-2} \cdot \mathrm{yr}^{-1}$ during $P_{3}$. The sediment yield reductions brought about by streamflow and SSC changes were $-1050 \mathrm{t} \cdot \mathrm{km}^{-2} \cdot \mathrm{yr}^{-1}$ and $-388 \mathrm{t} \cdot \mathrm{km}^{-2} \cdot \mathrm{yr}^{-1}$ during $P_{2},-2038 \mathrm{t} \cdot \mathrm{km}^{-2}$ $\cdot \mathrm{yr}^{-1}$ and $-711 \mathrm{t} \cdot \mathrm{km}^{-2} \cdot \mathrm{yr}^{-1}$ during $P_{3}$. The finding denotes again that both streamflow and SSC changes resulted in sediment load reduction in the middle reaches of Yellow River. Besides, the increased mean annual sediment load at the Zhangcunyi station was entirely attributed to the increase in SSC (Table 5). 

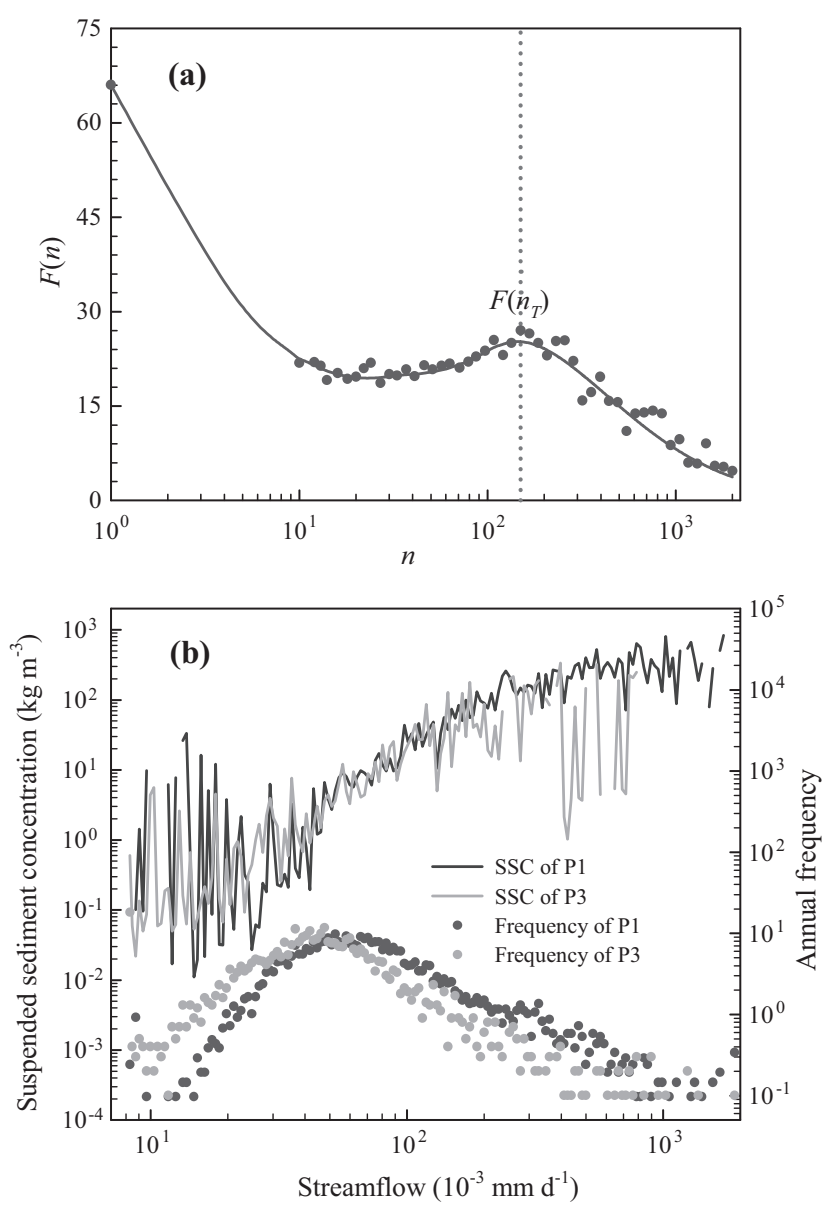

Fig. 9. The procedure for calculating the proportional sediment load change attributed to changing in SSC, using data of $P_{1}$ and $P_{3}$ from Zhuangtou station. (a) The calculated $F(n)$ varies with increasing $n$ in the calculating procedure. (b) The sediment rating curves and SSC frequency for both $P_{1}$ and $P_{3}$ at discharge classes $n_{T}=166$.

\section{Discussions}

\subsection{The potential changes in sediment load}

Studies noted that the Loess Plateau in ancient China was an area of lush grasslands and dense forests, and its forest cover was over $50 \%$ greater in the past (Feng et al., 2006; Lü et al., 2003; Meng, 1996; Wang, 1990; Zhang et al., 2010). However, vegetation was destroyed by severe soil and water erosion due to deforestation by humans (Chen et al., 2007; Fu et al., 2007; Shi and Shao, 2000). Long-term field plot experiments carried out in the catchment above Zhangcunyi (forested area) noted that erosion rates in the deforested lands increased to approximately 1000 times those in the forested land prior to deforestation, approximately $10,000-24,000 \mathrm{t} \cdot \mathrm{km}^{-2} \cdot \mathrm{yr}^{-1}$ (Zheng, 2006). It was therefore noted that vegetation is one of the predominant factors affecting soil erosion at the plot scale. As shown in Table 1 and Fig. 3, the annual mean sediment load in the forested area (Zhangcunyi and Huangling) is below the soil loss tolerance $\left(500 \mathrm{t} \cdot \mathrm{km}^{-2} \cdot \mathrm{yr}^{-1}\right)$, approximately $200 \mathrm{t} \cdot \mathrm{km}^{-2} \cdot \mathrm{yr}^{-1}$ over past 60 years. This value implies that soil and water conservation could be achieved by well-preserved vegetation on the regional scale, and it is also a scientific basis for the ecological restoration of the Loess Plateau (Ran et al., 2000; Tang, 2004; Zheng, 2006).

The eco-environment of the Loess Plateau was generally reported to be improved with the implementation of integrated soil conservation. However, partial deterioration of the ecoenvironment was also observed in Loess Plateau in the 1980s (Ran et al., 2000; Tang, 2004; Zhang et al., 2010). Investigations noted that forest vegetation in Zhiwuling was unfortunately damaged in this period, and the forest boundary line was retreating at an annual average rate of $0.5 \mathrm{~km}$ (Cai, 2001). As a result, rainfall erosion increased in these deforested fields, and the sediment delivered into the river channel increased. This pattern is the reason why sediment yield increased in the catchment above Zhangcunyi in the 1990s and early 2000s (Fig. 3).

As noted by Zhu et al. (2015), the restoration strategies led to large areas of mono-specific vegetation in $P_{2}$, and streamflow had not been substantially conserved by revegetation. The use of a sediment-trapping dam is a long-standing approach to controlling sediment yields, and it contributed approximately $60-70 \%$ of sediment load reduction during $P_{2}$ across eroding gullies and smaller tributaries (Ran et al., 2000; Zhang et al., 1997; Zheng, 2006). Generally, no runoff is generated on slopes, and little sediment is suspended in streamflow during non-rainy days in small watersheds (Zhang et al., 1997). Therefore, the sediment transformation in the mainstream is predominantly not influenced by ecological management actions on non-rainy days. This process explains why changes in low SSC and sediment yield (Fig. 4 e and $4 \mathrm{f}, 80 \% \sim 100 \%$ ) had no obvious regularity at the Jiaokouhe and Zhuangtou stations. As noted by Rustomji et al. (2008), the remobilization of in-channel sediment stores can represent an important sediment source which could continue to maintain high fluvial sediment loads. Because $80 \%$ of sediment-trapping dams were filled up or destroyed in the early $1980 \mathrm{~s}$ in northern Shaanxi province, some of the damaged dams did indeed provide such a sediment source. This source was reflected by increases in event SSC during storms with return periods of $0.1 \sim 0.3$ years in catchments above Wuqi in $P_{2}$ (Fig. 7b).

\subsection{Phases of sediment yield reduction}

Aside from the results above, three phases can be seen in sediment load reduction processes over the past 60 years:

In Phase 1, sediment load was effectively reduced by blocking hyperconcentrated flows and depositing SSC immediately when engineering works were finished. In the late $1970 \mathrm{~s}$ and early 1980 s, revegetation was not dense enough to effectively conserve soil and water. However, sediment load decreased (Table 3) mainly

Table 5

Streamflow and suspended sediment concentration changes contributed to sediment yield changes.

\begin{tabular}{|c|c|c|c|c|c|c|c|c|c|}
\hline \multirow[t]{2}{*}{ Stations } & \multicolumn{3}{|c|}{ Mean annual sediment } & \multicolumn{3}{|c|}{ Soil conservation period } & \multicolumn{3}{|c|}{ "Grain for Green period" period } \\
\hline & $\begin{array}{l}P_{1} \\
\left(\mathrm{t} \cdot \mathrm{km}^{-2} \cdot \mathrm{a}^{-1}\right)\end{array}$ & $\begin{array}{l}P_{2} \\
\left(\mathrm{t} \cdot \mathrm{km}^{-2} \cdot \mathrm{a}^{-1}\right)\end{array}$ & $\begin{array}{l}P_{3} \\
\left(\mathrm{t} \cdot \mathrm{km}^{-2} \cdot \mathrm{a}^{-1}\right)\end{array}$ & $\begin{array}{l}\Delta \Phi^{\text {flow }} \\
\left(\mathrm{t} \cdot \mathrm{km}^{-2} \cdot \mathrm{a}^{-1}\right)\end{array}$ & $\begin{array}{l}\Delta \Phi^{\mathrm{SSC}} \\
\left(\mathrm{t} \cdot \mathrm{km}^{-2} \cdot \mathrm{a}^{-1}\right)\end{array}$ & $\begin{array}{l}P_{\Delta \Phi^{\mathrm{SSC}}} \\
(\%)\end{array}$ & $\begin{array}{l}\Delta \Phi^{\text {flow }} \\
\left(\mathrm{t} \cdot \mathrm{km}^{-2} \cdot \mathrm{a}^{-1}\right)\end{array}$ & $\begin{array}{l}\Delta \Phi^{\mathrm{SSC}} \\
\left(\mathrm{t} \cdot \mathrm{km}^{-2} \cdot \mathrm{a}^{-1}\right)\end{array}$ & $\begin{array}{l}P_{\Delta \Phi^{\mathrm{SSC}}} \\
(\%)\end{array}$ \\
\hline Wuqi & 13,529 & 10,353 & 2304 & -2622 & -554 & 17.4 & -9108 & -2117 & 18.9 \\
\hline Liujiahe & 11,990 & 9223 & 4191 & -2532 & -235 & 8.5 & -6629 & -1170 & 15.0 \\
\hline Zhangcunyi & 91 & 166 & 345 & 23 & 52 & 87.6 & 34 & 288 & 113.3 \\
\hline Huangling & 496 & 126 & 67 & -160 & -210 & 56.8 & -207 & -222 & 51.7 \\
\hline Jiaokou & 5216 & 4179 & 2388 & -759 & -278 & 26.8 & -2293 & -535 & 18.9 \\
\hline Zhuangtou & 3876 & 2438 & 1127 & -1050 & -388 & 27.0 & -2038 & -711 & 25.9 \\
\hline
\end{tabular}


by reducing high daily/event streamflow and SSC (Figs. 4 and 5). In this period, sediment load decrease was mainly attributed to sediment-trapping dams, accounting for approximately $70 \%$ of the decrease (Ran et al., 2000; Zhang et al., 2010b; Zhang et al., 1997).

In Phase 2, sediment yields were continually intercepted, whereas some damaged dams presented as sources for sediment remobilization. As noted above, $80 \%$ of sediment-trapping dams were filled up or destroyed due to poor construction quality. It was noted by Rustomji et al. (2008) that sediment stores are likely to be relatively large given the high historic yields. Thus, as discussed above, some damaged dams served as sources for sediment remobilization in the late 1980 s and early1990s. This fact was demonstrated by a survey that showed that some of the damaged dams represent an important sediment source (Ma et al., 2011), although many of the damaged dams were repaired or reinforced.

In Phase 3, accumulated ecological restoration effectively reduced sediment load. Better soil structure with greater resistance to shearing and higher wash durability was normally formed on wasteland, grassland, forestland and derelict land (Cai, 2001; Tang, 2004). Vegetation effects on runoff and silt reduction will be efficient only if accumulated vegetation coverage exceeds a critical value - 15-20\% (Cai, 2001; Zhang et al., 2008). Plot experiments showed that soil and water were significantly reduced by $54 \%$ and $79 \%$ when the vegetation coverage by grasses was $20 \%$ and 40\%, respectively (Cai et al., 1992; Zeng and Ma, 1990). As noted by Zhu et al. (2015), the restoration strategy in the 2000s was improved by incorporating community functional diversity into the restoration design. It was noted that vegetation recovery in the Loess Plateau was the best in China and statistically significant in recent years (Lü et al., 2003). Moreover, vegetation restoration has progressed for $>30$ years, accompanied by vegetation succession. Regional-scale streamflow, SSC and sediment yield all decreased effectively in $P_{3}$, at annual (Table 3), daily (Fig. 4) and event (Fig. 7) timescales.

\subsection{Phases of soil erosion aggravation}

The erosion intensity throughout history was no doubt much lower than that at present in the Loess Plateau, with increasingly serious erosion resulting from human destruction of vegetation (Cai, 2001; Shi et al., 2002; Shi and Shao, 2000). Field plot experiments showed that human destruction of vegetation can happen over a short period or an extremely short period; however, the aggravation of human-induced soil erosion would be several hundred times more serious than natural erosion (Zheng, 2006; Zheng et al., 2005). The increased annual sediment yield at the Zhangcunyi station exposed a risk of erosion aggravation. The daily and event timescale sediment load and SSC changes potentially led to two phases in sediment increase at the regional (basin-wide) scale:

Phase 1: High daily sediment yield is aggravated, while moderate and low sediment yield persists. There are generally no runoff and sediment yields generated on deforested slopes on non-rainy days. However, rill erosion and shallow landslides are activated once a rainfall threshold is exceeded; then, shallow gullies gradually become gullies (Hicks et al., 2000; Zheng, 2006). Deforestation is sporadically distributed in the early days of deforestation, and river sediment load is very low. Sediment transported from these fields therefore increased in-channel SSC and sediment load. This process was reflected at the regional scale by the increasing sediment load at Zhangcunyi.

Phase 2: Sediment yield is seriously aggravated at all magnitudes. Farmland expansion under population pressure resulted in wide-reaching vegetation devastation over the past 3000 years. In the 1950s, vegetation in most parts of the region of the Loess Plateau was devastated, natural balance became disordered, and soil erosion aggravation far exceeded natural erosion (Cai, 2001). As noted by Zheng (2006), the secondary forests in Ziwuling have been naturally restored over the past 140 years. The catchments above Zhangcunyi and Wuqi are similar in their landforms, with a shallow gully density of approximately $20-40 \mathrm{~km} \cdot \mathrm{km}^{-2}$ (Zheng, 2006). However, the sediment yield at Wuqi in $P_{1}$ was $13,529 \mathrm{t} \cdot \mathrm{km}^{-2} \cdot \mathrm{yr}^{-1}$, while at Huangling (forested area) it was only $91 \mathrm{t} \cdot \mathrm{km}^{-2} \cdot \mathrm{yr}^{-1}$ (Fig. 3 and Table 5). The comparison may exhibit how sediment yield exploded as only sporadic forests were distributed in the vast expanse of the Loess Plateau.

Overall, it was an urgent mission in the $1950 \mathrm{~s}$ to expeditiously control serious sediment deposition and disastrous flooding. Consequently, sediment-trapping dams were built for immediate sediment interception. The daily and event sediment yield changes in $P_{2}$ showed that high sediment loads effectively decreased, mainly due to retention by dams (Ran et al., 2000; Zhang et al., 2010). Obviously, sediment-trapping dams did not have much influence on slope erosion (Xu et al., 2004). Thus, sediment-trapping dams may not be a measure for the substantial reduction of sediment yields. The significant reduction in sediment load at all magnitudes in $P_{3}$ indicates that vegetation is an optimal measure with which to conserve soil and water.

As noted by Zhang et al. (2001a, 2001b), the hydrological regime in a basin is generally constant over a long period of time (i.e., 10 years or longer); in other words, the probability distribution curve of the mean SSC versus a discharge class is generally fixed unless the underlying surface changes. Obviously, the changes in streamflow are induced by both anthropogenic impacts and climate variation. However, it is thought that the changes in SSC calculated from the SSC-water discharge distribution are independently induced by anthropogenic impacts. The enlarged sediment yield reduction due to changes in SSC (Table 5) indicates that the streamflow in the middle Yellow River is becoming cleaner.

\section{Conclusions}

This study examined the role that changes in streamflow and SSC-water discharge relationships have played in altering the sediment load in the middle reaches of the Yellow River, which originates in the Loess Plateau, using data from the 1950s to 2009. Statistically significant negative trends for annual sediment yield and SSC were identified at 5 out of 6 stations. The trends in annual sediment yield varied from -4 to $-217 \mathrm{t} \cdot \mathrm{km}^{-2} \cdot \mathrm{yr}^{-1}$, and the trends in annual SSC varied from -0.08 to $-6.77 \mathrm{~kg} \cdot \mathrm{m}^{-3} \cdot \mathrm{yr}^{-1}$. Change point years for annual SSC were consistent with the change point years identified for annual sediment yield.

Sediment loads have decreased continuously in the context of the continuously underlying surface changed by ecological restoration. The sediment yield was reduced mainly by decreases in high flow and high SSC conditions during $P_{2}$, while sediment yield decreased dramatically at all magnitudes during $P_{3}$, regardless of whether annual, daily and event timescales were analyzed. The sediment yield changed from $3876 \mathrm{t} \cdot \mathrm{km}^{-2} \cdot \mathrm{yr}^{-1}$ in $P_{1}$ to $1127 \mathrm{t} \cdot \mathrm{km}^{-2} \cdot \mathrm{yr}^{-1}$ in $P_{3}$ in the entire basin. The sediment yield reductions attributed to streamflow reduction and SSC changes were $-1050,-388 \mathrm{t} \cdot \mathrm{km}^{-2} \cdot \mathrm{yr}^{-1}$ in $P_{2}$, and $-2038,-711 \mathrm{t} \cdot \mathrm{km}^{-2} \cdot \mathrm{yr}^{-1}$ in $P_{3}$, respectively.

It was concluded that ecological restoration have changed rainfall-streamflow, rainfall-SSC and rainfall-sediment load dynamics. Both streamflow reduction and SSC-water discharge relationship change induced a sediment load reduction; in other words, the muddy water in the middle reaches of Yellow River run clearer. Besides, the increased annual sediment yield at the Zhangcunyi station exposed a risk of erosion aggravation in an area where vegetation had been well preserved. 


\section{Acknowledgements:}

This study is supported by the National Natural Science Foundation of China (Grant nos. 41230852, 41440012, 41101265), and the Special-Funds of Scientific Research Programs of State Key Laboratory of Soil Erosion and Dryland Farming on the Loess Plateau (A314021403-C2). Thanks are given to two anonymous reviewers for their constructive comments.

\section{References}

Bowerman, B.L., O’Connell, R.T., 1979. Time Series and Forecasting: An Applied Approach. Duxbury Press Wadsworth, Belmont, California.

Brown, A.E., Zhang, L., McMahon, T.A., Western, A.W., Vertessy, R.A., 2005. A review of paired catchment studies for determining changes in water yield resulting from alterations in vegetation. J. Hydrol. 310 (1-4), 28-61.

Cai, Q., 2001. Soil erosion and management on the Loess Plateau. J. Geogr. Sci. 11 (1), $53-70$.

Cai, Q., Wu, S., Chen, H., Ma, S., 1992. Impact of steep slope grass planting on runoff erosion induced silt yield. In: Study on Surface Material Migrational Law in Huanghe Drainage Basin and Geomorphologic Formation Process. Geological Press, Beijing.

Chen, L., Wei, W., Fu, B., Lü, Y., 2007. Soil and water conservation on the Loes Plateau in China: review and perspective. Prog. Phys. Geog. 31 (4), 389-403.

CMWR (Ministry of Water Resource of PR China), 2003. Programming for check dams in the Loess Plateau (Technical Report). pp. 47-48 (in Chinese).

Cochrane, D., Orcutt, G.H., 1949. Application of least squares regression to relationships containing auto-correlated error terms. J. Am. Stat. Assoc. 44 (245), 32-61.

Derbyshire, E., Meng, X., Dijkstra, T.A., 2000. Landslides in the Thick Loess Terrain of North-West China. John Wiley \& Sons Incorporated, Chichester.

Du, H., Wu, Z., Zong, S., Meng, X., Wang, L., 2013. Assessing the characteristics of extreme precipitation over Northeast China using the multifractal detrended fluctuation analysis. J. Geophys. Res.: Atmos. 118. http://dx.doi.org/10.1002/ jgrd.50487.

Feng, Z.D., Tang, L.Y., Wang, H.B., Ma, Y.Z., Liu, K.B., 2006. Holocene vegetation variations and the associated environmental changes in the western part of the Chinese Loess Plateau. Palaeogeogr. Palaeocl. 241 (3), 440-456.

Fu, G., Charles, S.P., Viney, N.R., Chen, S., Wu, J.Q., 2007. Impacts of climate variability on stream-flow in the Yellow River. Hydrol. Process. 21 (25), 3431-3439.

Gao, Z. et al., 2012. Trends of streamflow, sediment load and their dynamic relation for the catchments in the middle reaches of the Yellow River over the past five decades. Hydrol. Earth Syst. Sci. 16 (9), 3219-3231.

Hicks, D.M., Gomez, B., Trustrum, N.A., 2000. Erosion thresholds and suspended sediment yields, Waipaoa River basin, New Zealand. Water Resour. Res. 36 (4), 1129-1142.

Kendall, M., 1975. Rank Correlation Methods. Griffin, London, UK.

Lü, H., Liu, D., Guo, Z., 2003. Natural vegetation of geological and historical periods in Loess Plateau. Chin. Sci. Bull. 48 (5), 411-416.

Li, G., 2003. Ponderation and Practice of the Yellow River control. Yellow River Conservancy Press. 271.

Liao, J., Xu, J., Yang, Y., 2008. Study of the spatial differentiation of hyperconcentrated flows frequency in the Loess Plateau. Adv. Water Sci. 19 (2), 160-170 (in Chinese).

Ma, N., Zhu, S., Wang, P., 2011. Field Survey and Analysis on Status of Large and Medium Sized Check-Dams in Northern Shaanxi Province. Bull. Soil Water Conserv. 31 (3), 155-160 (in Chinese).

Mann, H.B., 1945. Nonparametric tests against trend. Econometrica, 245-259.

Meng, Q., 1996. Soil and Water Conservation in the Loess Plateau, 75. Yellow River Water Conservancy Press, Zhengzhou (in Chinese).

Mi, D., 1982. The situation of forestry destroy in Ziwuling and its effects in recent years. Bull. Soil Water Conserv. 5, 19-23 (in Chinese).

Mu, X., Zhang, L., McVicar, T.R., Chille, B., Gau, P., 2007. Analysis of the impact of conservation measures on stream flow regime in catchments of the Loess Plateau, China. Hydrol. Process. 21 (16), 2124-2134.

Oliver, M.A., Webster, R., 1990. Kriging: a method of interpolation for geographica information systems. Int. J. Geogr. Inf. Sci. 4 (3), 313-332.

Pettitt, A., 1979. A non-parametric approach to the change-point problem. J. Appl. Stat., $126-235$

Pimentel, D. et al., 1995. Environmental and economic costs of soil erosion and conservation benefits. Science, pp. 1117-1117.

Quinton, J.N., Edwards, G.M., Morgan, R.P.C., 1997. The influence of vegetation species and plant properties on runoff and soil erosion: results from a rainfal simulation study in south east Spain. Soil Use Manage. 13 (3), 143-148.

Ran, D. et al., 2000. The Soil Conservation Practices and Streamflow and Sediment Load Changes in the Hekou-Longmen Region of Middle Reaches of Yellow River. Yellow River Water Conservancy Press, Zhengzhou (in Chinese).

Ran, D., Zuo, Z., Wu, Y., Li, X., Li, Z., 2012. Streamflow and Sediment Load Changes Response to Human Activites in the Middle Reaches of the Yellow River. Science China Press, Beijing (in Chinese).

Ran, L., Lu, X., Xin, Z., Yang, X., 2013. Cumulative sediment trapping by reservoirs in large river basins: a case study of the Yellow River basin. Global Planet. Change $100,308-319$.
Rustomji, P., Zhang, X., Hairsine, P., Zhang, L., Zhao, J., 2008. River sediment load and concentration responses to changes in hydrology and catchment management in the Loess Plateau region of China. Water Resour. Res. 44 (7). http://dx.doi.org/ 10.1029/2007WR006656.

Sahin, V., Hall, M.J., 1996. The effects of afforestation and deforestation on water yields. J. Hydrol. 178 (1-4), 293-309.

Sen, P.K., 1968. Estimates of the regression coefficient based on Kendall's tau. J. Am. Stat. Assoc. 63 (324), 1379-1389.

Shi, C., Dian, Z., You, L., 2002. Changes in sediment yield of the Yellow River basin of China during the Holocene. Geomorphology 46 (3), 267-283.

Shi, H., Shao, M., 2000. Soil and water loss from the Loess Plateau in China. J. Arid Environ. 45 (1), 9-20.

Tang, K., 1993. The Changes of Erosion, Runoff and Sediment in the Yellow River. Science China Press, Beijing (in Chinese).

Tang, K., 2004. Soil and Water Conservation in China. Science China Press, Beijing (in Chinese).

Wang, G., Wu, B., Wang, Z.Y., 2005. Sedimentation problems and management strategies of Sanmenxia Reservoir, Yellow River, China. Water Resour. Res. 41 (9). http://dx.doi.org/10.1029/2004WR003919.

Wang, S., 1990. On Loess Plateau vegetation in ancient times. Geogr. Res. 19 (4), $73-$ 79 (in Chinese).

Wang, S., Unwin, D.J., 1992. Modelling landslide distribution on loess soils in China: an investigation. Int. J. Geogr. Inf. Sci. 6 (5), 391-405.

Wang, Y., Fu, B., Chen, L., Lü, Y., Gao, Y., 2011. Check dam in the Loess Plateau of China: engineering for environmental services and food security. Environ. Sci. Technol. 45 (24), 10298-10299.

Wang, Y., Li, J., Liang, H., 2006. Granularity change in lower Yellow River channel. Soil Water Conserv. 2006 (8), 14-23 (in Chinese).

Wilcox, B.P., Huang, Y., Walker, J.W., 2008. Long-term trends in streamflow from semiarid rangelands: uncovering drivers of change. Global Change Biol. 14 (7), $1676-1689$.

Xu, J., 1994. Zonal distribution of river basin erosion and sediment yield in China. Chin. Sci. Bull. 39 (16), 1356-1361.

$\mathrm{Xu}, \mathrm{J.}$., 2002. Influence of human activities on hyperconcentrated flows in the middle Yellow River. Sci. Geogr. Sin. 22 (3), 294-299 (in Chinese).

Xu, X., Zhang, H., Zhang, O., 2004. Development of check-dam systems in gullies on the Loess Plateau, China. Environ. Sci. Policy 7 (2), 79-86.

Yao, W., Li, Z.B., Kang, L.L., Ran, D., 2005. The Effects of Controlling Soil Erosion on Environment on the Loess Plateau. Science and Technology Press (in Chinese).

Yao, W., Xu, J., Ran, D., 2011. Analysis and Evaluation of the Water Sand Changing Regime in Catchments of Yellow River Basin. Yellow River Water Conservancy Press, Zhengzhou (in Chinese).

Zeng, B., Ma, W., 1990. Study on impact of artificial grass coverage on water-borne silt yield. In: Collected Papers on Sino-Canada Study of Soil Erosion Regularity on Loess Plateau of West Shanxi, China. Water and Hydropower Publishing House, Beijing (in Chinese).

Zhang, K., Zhao, Y., Zhou, A., Sun, H., 2010. Late Holocene vegetation dynamic and human activities reconstructed from lake records in western Loess Plateau, China. Quatern. Int. 227 (1), 38-45.

Zhang, J., Zhang, T., Lei, Y., Zhang, X., Li, R., 2016. Streamflow regime variations following ecological management on the Loess Plateau, China. Forests 7 (1), pp. $6,1-18$.

Zhang, L., Dawes, W., Walker, G., 2001a. Response of mean annual evapotranspiration to vegetation changes at catchment scale. Water Resour. Res. 37 (3), 701-708.

Zhang, T., Zhang, J., Guo, M., Chen, L., Zhang, X., 2014. Trend of streamflow and its controlling factor under the regional vegetation restoration in Beiluo River basin. J. Soil Water Conserv. 28 (4), 78-84 (in Chinese).

Zhang, X., Harvey, K.D., Hogg, W., Yuzyk, T.R., 2001b. Trends in Canadian streamflow. Water Resour. Res. 37 (4), 987-998.

Zhang, X., Walling, D., Quine, T., Wen, A., 1997. Use of reservoir deposits and caesium-137 measurements to investigate the erosional response of a small drainage basin in the rolling loess plateau region of China. Land Degrad. Dev. 8 (1), 1-16.

Zhang, X., Zhang, L., Zhao, J., Rustomji, P., Hairsine, P., 2008. Responses of streamflow to changes in climate and land use/cover in the Loess Plateau, China. Water Resour. Res. 44 (7). http://dx.doi.org/10.1029/2007WR006711.

Zhao, G. et al., 2014. Quantifying the impact of climate variability and human activities on streamflow in the middle reaches of the Yellow River basin, China. J. Hydrol. 519, 387-398.

Zheng, F.L., 2006. Effect of vegetation changes on soil erosion on the Loess Plateau. Pedosphere 16 (4), 420-427.

Zheng, F.L., He, X.B., Gao, X.T., Zhang, C., Tang, K.L., 2005. Effects of erosion patterns on nutrient loss following deforestation on the Loess Plateau of China. Agric. Ecosyst. Environ. 108 (1), 85-97.

Zheng, M., Cai, Q., Cheng, Q., 2008. Modelling the runoff-sediment yield relationship using a proportional function in hilly areas of the Loess Plateau, North China. Geomorphology 93 (3), 288-301.

Zheng, M., Cai, Q., Wang, C., Liu, J., 2007. Effect of vegetation and other measures for soil and water conservation on runoff-sediment relationship in watershed scale. J. Hydraul. Eng. 38 (1), 47-53.

Zhou, J., Zhu, C., Zheng, J., Wang, X., Liu, Z., 2002. Landslide disaster in the loess area of China. J. For. Res. 13 (2), 157-161.

Zhu, H. et al., 2015. Reducing soil erosion by improving community functional diversity in semi-arid grasslands. J. Appl. Ecol. http://dx.doi.org/10.1111/13652664.12442. 